\title{
Insulin resistance, lipotoxicity, type 2 diabetes and atherosclerosis: the missing links. The Claude Bernard Lecture 2009
}

\author{
R. A. DeFronzo
}

Received: 20 November 2009/Accepted: 22 December 2009/Published online: 2 April 2010

(C) The Author(s) 2010. This article is published with open access at Springerlink.com

\begin{abstract}
Insulin resistance is a hallmark of type 2 diabetes mellitus and is associated with a metabolic and cardiovascular cluster of disorders (dyslipidaemia, hypertension, obesity [especially visceral], glucose intolerance, endothelial dysfunction), each of which is an independent risk factor for cardiovascular disease (CVD). Multiple prospective studies have documented an association between insulin resistance and accelerated CVD in patients with type 2 diabetes, as well as in non-diabetic individuals. The molecular causes of insulin resistance, i.e. impaired insulin signalling through the phosphoinositol-3 kinase pathway with intact signalling through the mitogen-activated protein kinase pathway, are responsible for the impairment in insulin-stimulated glucose metabolism and contribute to the accelerated rate of CVD in type 2 diabetes patients. The current epidemic of diabetes is being driven by the obesity epidemic, which represents a state of tissue fat overload. Accumulation of toxic lipid metabolites (fatty acyl CoA, diacylglycerol, ceramide) in muscle, liver, adipocytes, beta cells and arterial tissues contributes to insulin resistance, beta cell dysfunction and accelerated atherosclerosis, respectively, in type 2 diabetes. Treatment with thiazolidinediones mobilises fat out of tissues, leading to enhanced insulin sensitivity, improved beta cell function and decreased atherogenesis. Insulin resistance and lipotoxicity represent the missing links (beyond the classical cardiovascular risk factors) that help explain the accelerated rate of CVD in type 2 diabetic patients.
\end{abstract}

Keywords Cardiovascular disease $\cdot$ Endothelial dysfunction · Insulin resistance $\cdot$ Insulin signalling · Lipotoxicity · Obesity $\cdot$ Review $\cdot$ Type 2 diabetes

\footnotetext{
R. A. DeFronzo $(\triangle)$

Diabetes Division,

University of Texas Health Science Center at San Antonio,

7703 Floyd Curl Drive-MSC 7886,

San Antonio, TX 78229, USA

e-mail: Albarado@uthscsa.edu
}

\author{
Abbreviations \\ ACCORD Action to Control Cardiovascular Risk in \\ Diabetes \\ ADVANCE Action in Diabetes and Vascular Disease: \\ Preterax and Diamicron MR Controlled \\ Evaluation \\ CVD Cardiovascular disease \\ ERK Extracellular regulated kinase \\ HOMA-IR HOMA of insulin resistance \\ IkB Inhibitor $\mathrm{k} \beta$ \\ MAP Mitogen-activated protein \\ NF-kB Nuclear factor $k \beta$ \\ PDGF Platelet-derived growth factor \\ PGC-1 PPAR $\gamma$ coactivator-1 \\ PI Phosphoinositol \\ PKC Protein kinase C \\ PPAR Peroxisome proliferator-activated receptor \\ VADT Veterans Administration Diabetes Trial \\ VSMC Vascular smooth muscle cells
}

\section{Introduction}

Type 2 diabetes mellitus is a complex metabolic disorder complicated by microvascular and macrovascular disease [1]. Hyperglycaemia is the major risk factor for microvascular complications $[2,3]$ and reduction in $\mathrm{HbA}_{1 \mathrm{c}}$ decreases the incidence of retinopathy, nephropathy and neuropathy $[2,3]$. For every $1 \%$ decrement in $\mathrm{HbA}_{1 \mathrm{c}}$, the incidence of microvascular complications is reduced by $\sim 25 \%$ to $35 \%$. Although microvascular complications are a major cause of morbidity, macrovascular complications represent the primary cause of mortality with heart attacks and stroke accounting for around $80 \%$ of all deaths [4]. In type 2 diabetic patients without prior history of myocardial infarction, the 7-year incidence of myocardial infarction is equal to or greater than 
the 7-year incidence of heart attack in non-diabetic individuals with prior myocardial infarction [5]. In diabetic patients with a previous heart attack, the 7-year incidence of subsequent myocardial infarction is more than double $(45 \%)$ that of non-diabetic individuals [5]. Similarly, the recurrence rate of major atherosclerotic complications in type 2 diabetic patients with a prior cardiovascular event is very high, around $6 \%$ per year [6]. These results document that diabetes is a cardiovascular equivalent.

\section{Hyperglycaemia and cardiovascular disease}

Given the above observations and the negative results of the ACCORD [7], ADVANCE [8] and VADT [9] studies, in which intensified glycaemic control failed to reduce macrovascular complications, it is reasonable to ask what role hyperglycaemia plays in the development of cardiovascular disease (CVD). Epidemiological analysis of the UKPDS [3] demonstrated that rising $\mathrm{HbA}_{1 \mathrm{c}}$ was associated with increased risk of myocardial infarction and stroke. However, the increased hazard ratio was modest and reduction in $\mathrm{HbA}_{1 \mathrm{c}}$ following insulin or sulfonylurea therapy did not significantly decrease myocardial infarctions or strokes [10], although long-term follow up did demonstrate a significant reduction in atherosclerotic cardiovascular events [11]. These results suggest a 'memory' effect of improved glycaemic control, reminiscent of the Diabetes Control and Complications Trial in type 1 diabetic patients [12].

The negative results of the ACCORD, ADVANCE and VADT [7-9] studies have also led to questioning of the notion that improved glycaemic control prevents macrovascular complications in type 2 diabetic patients, especially in those with long-standing diabetes. What, for example, could explain the failure to observe a reduction in macrovascular events in these studies (see textbox: Insulin and atherosclerosis)?

\section{Insulin and atherosclerosis}

Insulin:

- enhances VLDL synthesis and may reduce

HDL-cholesterol levels

- increases cholesterol transport into arteriolar smooth muscle cells

- is a growth factor that: - augments collagen synthesis - stimulates proliferation of arteriolar smooth muscle cells

- promotes atherogenesis in animal models (rabbit, chicken, dog)

- causes insulin resistance
First, the underlying hypothesis is not based on sound pathophysiological evidence. Hyperglycaemia is a weak risk factor for CVD compared with other well established risk factors, e.g. dyslipidaemia and hypertension; moreover, most patients in the above studies were being treated with lipidlowering medications, antihypertensive drugs and antiinflammatory agents [7-9]. Second, participants had longstanding diabetes with a prior cardiovascular event or multiple risk factors for CVD. Third, insulin may be the wrong drug for prevention of CVD. Insulin is associated with weight gain $[13,14]$ and weight gain (obesity) is a major risk factor for CVD [15, 16]. Moreover, even small increments in plasma insulin cause severe insulin resistance $[17,18]$, which is also a risk factor for CVD. Fourth, the study population, although large in the ACCORD and ADVANCE studies, was inadequate, given the low annual incidence of cardiovascular complications ( $2 \%$ per year), to demonstrate a beneficial effect of improved glycaemic control.

\section{Insulin and atherosclerosis}

Many in vivo and in vitro studies have demonstrated that insulin, especially at high doses, can promote atherogenesis [19-21] (see textbox: Insulin and atherosclerosis). Insulin promotes de novo lipogenesis and augments hepatic VLDL synthesis [22, 23] via its stimulation of sterol regulatoryelement-binding protein-1c and its inhibition of acetyl-CoA carboxylase [24]. In cultured arterial smooth muscle cells, insulin augmented LDL-cholesterol transport [25]. Insulin is a potent growth factor, augments collagen synthesis [26, 27], stimulates arterial smooth muscle cell proliferation [28, 29 ] and turns on multiple genes involved in inflammation [27].

In vivo studies in dogs [30], rabbits [31] and chickens [32] provide further evidence that insulin promotes atherogenesis. Non-diabetic chickens fed a high-cholesterol diet develop severe atherosclerosis, which regresses when switched to low-cholesterol diet [32]. Insulin administration when the low-cholesterol diet was instituted prevented regression of coronary atherosclerosis. Alloxan-induced diabetic rabbits fed a high-cholesterol diet developed marked hypercholesterolaemia, but their aorta remained free of atherosclerotic plaque [31]. If rabbits are treated with insulin, severe atherosclerosis develops. Dogs receiving a low-dose insulin infusion into a hindlimb artery (to cause local, physiological hyperinsulinaemia) developed severe femoral atherosclerosis, whereas all other arteries remained free of atherosclerotic plaque [30]. Rats chronically (7-10 days) infused with insulin while maintaining euglycaemia became markedly resistant to the stimulation of glucose uptake and suppression of plasma NEFA by insulin [23], and became hypertensive [33]. 
Two other points about hyperinsulinaemia are noteworthy. In humans with normal glucose tolerance, insulin infusion to raise fasting plasma insulin from 57 to $104 \mathrm{pmol} / 1$ for 3 days produced severe insulin resistance [17, 18], a risk factor for CVD (see subsequent discussion). Finally, insulin therapy is invariably associated with weight gain [13, 14]. Most studies designed to reduce $\mathrm{HbA}_{1 \mathrm{c}}<7.0 \%$ have required large insulin doses, failed to achieve the targeted $\mathrm{HbA}_{1 \mathrm{c}}$ goal and resulted in weight gain $[13,14]$. The study of Henry et al. [13] is especially noteworthy. $\mathrm{HbA}_{1 \mathrm{c}}$ was reduced from $7.7 \%$ to $5.1 \%$, but this was associated with weight gain of $8.6 \mathrm{~kg}$. This is of major concern since the current diabetes epidemic is being driven by obesity, a major risk factor for CVD [15, 16]. Weight gain promotes atherogenesis via multiple mechanisms including dyslipidaemia and hypertension. Fat deposition in the arterial wall promotes inflammation, which directly accelerates atherogenesis [34-37]. Interestingly, $27.8 \%$ of individuals in the intensive treatment arm of the ACCORD study gained $>10 \mathrm{~kg}$ [7].

\section{Insulin resistance (metabolic) syndrome}

Much evidence indicates that insulin resistance per se and associated components of the insulin resistance (metabolic) syndrome (see textbox: Syndrome of insulin resistance) [38-40] contribute to development of CVD. Studies from our laboratory (Fig. 1) [1, 9, 41-44] and others [45, 46] have demonstrated that lean type 2 diabetic and obese normal glucose tolerant participants are resistant to insulin and that their insulin resistance primarily affects the glycogen synthetic pathway. Type 2 diabetes $[4,5]$ and obesity $[15,16]$ are major cardiovascular risk factors. A common thread linking all components of the insulin resistance (metabolic) syndrome is the basic cellular/ molecular cause of insulin resistance [44], which not only promotes inflammation and atherogenesis, but leads to and/ or aggravates other components of the syndrome, which themselves are major CVD risk factors.

\section{Syndrome of insulin resistance}

- Obesity (especially visceral)

- Glucose intolerance (impaired glucose tolerance, impaired fasting glucose, type 2 diabetes mellitus)

- Hypertension

- Dyslipidaemia (high triacylglycerol, low HDL, small dense LDL particles)

- Endothelial dysfunction

- Atherosclerotic CVD

- Hyperinsulinaemia

- Insulin resistance
Hypertension is a central feature of the insulin resistance syndrome. Many studies have demonstrated that hypertensive individuals are resistant to insulin, primarily involving the glycogen synthetic pathway (Fig. 1) [47-51], and hypertension is a well established risk factor for CVD.

Type 2 diabetic and obese individuals develop dyslipidaemia characterised by hypertriacylglycerolaemia, reduced HDL-cholesterol, and small dense atherogenic LDL particles $[39,40,52,53]$, each of which is a major CVD risk factor. We and others [51, 54-57] have shown that hypertriacylglycerolaemia, but not hypercholesterolaemia is associated with insulin resistance primarily involving the glycogen synthetic pathway (Fig. 1). The frequency of hypercholesterolaemia is not increased in patients with type 2 diabetes mellitus [53]. However, if elevated, LDLcholesterol acts synergistically with other risk factors to accelerate atherogenesis [58].

To examine the relationship between insulin resistance and CVD, we compared normal glucose-tolerant individuals with diffuse coronary artery disease with normal glucose-tolerant participants with clean coronary arteries [59]. Individuals with coronary artery disease manifested marked insulin resistance, primarily affecting the glycogen synthetic pathway in skeletal muscle [59] (Fig. 1). Studies by Reaven [40] and Paternostro et al. [60] have demonstrated that non-diabetic individuals with established coronary artery disease are resistant to insulin. Using positron emission tomography, the myocardium of non-diabetic individuals with coronary artery disease [61] and type 2 diabetic patients without coronary artery disease [62] has been shown to be resistant to insulin.

In summary, each component of the 'metabolic' syndrome is characterised by insulin resistance involving the glycogen synthetic pathway (Fig. 1). Insulin resistance is present at the stage of impaired glucose tolerance $[63,64]$ and even before any abnormality in glucose tolerance is observed [65]. Thus, we prefer to refer to the metabolic and cardiovascular cluster of factors that comprise the 'metabolic' syndrome as the 'insulin resistance syndrome' [20, 21, 66]. This focuses clearly on a specific pathogenic aetiology, rather than on a diffuse cluster of factors that may or may not be related to the same underlying pathophysiology.

\section{Insulin resistance and the insulin resistance syndrome predict future cardiovascular disease}

Multiple prospective studies have demonstrated that insulin resistance predicts future CVD. In the San Antonio Heart Study [67], insulin resistance was quantitated by HOMA of insulin resistance (HOMA-IR) in 2,564 non-diabetic participants who were followed for 8 years. Individuals in the 


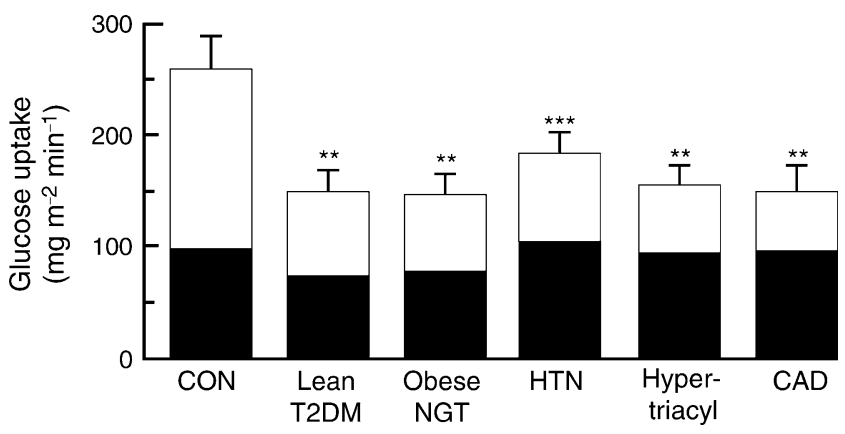

Fig. 1 Insulin-stimulated glucose disposal (40 $\mathrm{mU} \mathrm{m}^{-2} \mathrm{~min}^{-1}$, euglycaemic-hyperinsulaemic clamp) in lean healthy control (CON) participants, obese normal-glucose-tolerant participants (NGT), lean drug-naive type 2 diabetic participants (T2DM), lean normal-glucosetolerant hypertensive participants (HTN), NGT hypertriacylglycerolaemic (Hypertriacyl) participants and non-diabetic participants with coronary artery disease (CAD). White sections, non-oxidative glucose disposal (glycogen synthesis); black sections, glucose oxidation. ${ }^{* *} p$ $<0.01$ vs $\mathrm{CON} ; * * * p<0.001$ vs CON. Figure adapted with permission from Kashyap et al. [19] and DeFronzo et al. [20]. To change glucose uptake into SI units, divide by 180

highest quintile of insulin resistance had an approximately 2.5-fold increased incidence of CVD (Fig. 2a). After adjustment for multiple cardiovascular risk factors, individuals in the highest quintile of insulin resistance still had a twofold increased incidence of CVD. In 3,606 nondiabetic participants followed for 6.9 years in the Botnia Study [68] (Fig. 2b), the metabolic syndrome was associated with a threefold increased risk of CVD. Each component of the metabolic syndrome, as well as insulin resistance (HOMA-IR) itself, was associated with a 1.5- to 2 -fold increased incidence of CVD (Fig. 2b). Similar observations have been made in the Bruneck [69], Verona Diabetes [70] and Insulin Resistance Atherosclerosis studies [71]. A strong relationship between HOMA-IR and carotid intimal media thickness has also been demonstrated [72], as has an association between insulin resistance and greater cardiovascular risk factor load [73].

The analysis by D'Agostino et al. of six prospective studies further supports an independent role for insulin resistance in CVD [74]. It found that, using the Framingham Cardiovascular Risk Engine [75], only $69 \%$ of the observed risk for CVD could be explained, leaving 31\% unaccounted for (Fig. 3a). Similarly, in the ARIC study [76] (Fig. 3b), only $\sim 70 \%$ of the increase in carotid intimal media thickness could be accounted for by dyslipidaemia, hypertension, glucose intolerance and obesity. We hypothesise that this unexplained risk can be attributed to insulin resistance.

\section{Molecular causes of insulin resistance syndrome}

Normal insulin signalling As shown in Fig. 4a, for insulin to exert its biological effects, it must first bind to specific cell surface receptors [77, 78]. This activates 'second messengers', which initiate a phosphorylation-dephosphorylation cascade that stimulates glucose transport (via GLUT4), glucose phosphorylation (via hexokinase II), glycogen synthase (which controls glycogen synthesis) and both phosphofructokinase and pyruvate dehydrogenase (which regulate glycolysis and glucose oxidation) [79].

In muscle, insulin binding to its receptor [77, 79] leads to tyrosine phosphorylation of IRS-1, which mediates insulin's effect on glucose metabolism. In liver, IRS-2 phosphorylation mediates the actions of insulin. IRS-1 activates phosphatidylinositol (PI)-3 kinase [80], which catalyses 3 ' phosphorylation of PI, PI-4 phosphate and PI4,5 diphosphate, and augments glucose transport and glycogen synthase [81-83]. Inhibitors of PI-3 kinase inhibit glucose transport [82], hexokinase II [84] and glycogen synthase [85].

Insulin signalling also plays a critical role in activating nitric oxide synthase, which regulates nitric oxide production [86-88]. Nitric oxide is a potent vasodilator and anti-atherogenic agent [86]. Nitric oxide deficiency activates multiple pathways involved in atherogenesis $[89,90]$.

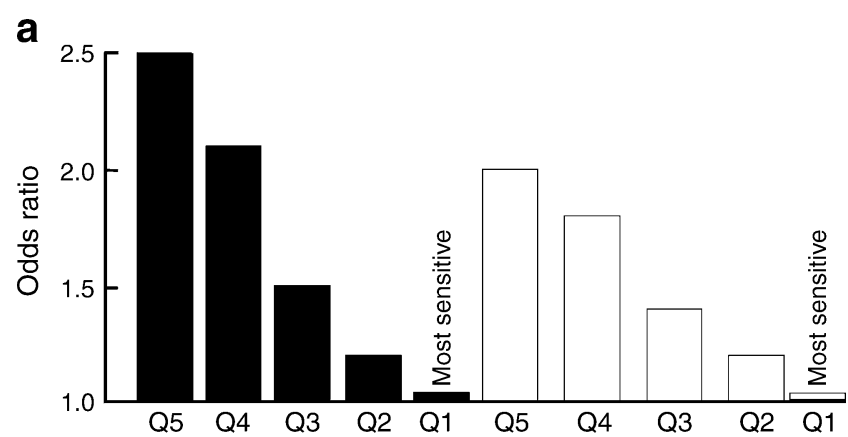

b

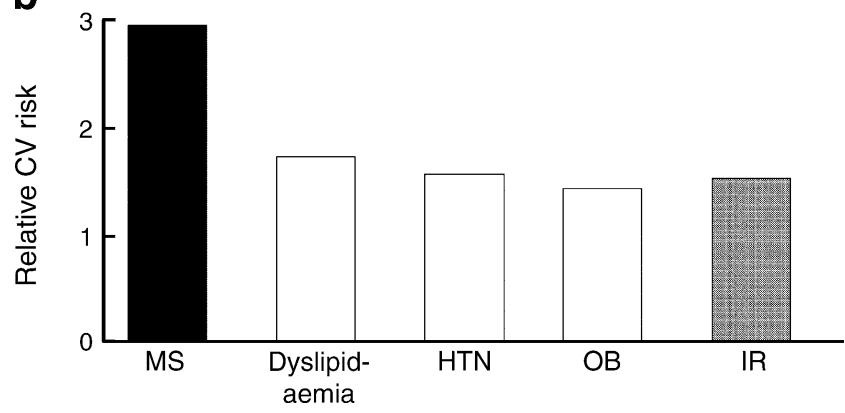

Fig. 2 a Association between insulin resistance (HOMA-IR) and 8year incidence of CVD in non-diabetic participants in the San Antonio Heart Study before (black bars) and after (white bars) adjustment for age, sex, blood pressure, plasma lipids, smoking, exercise and waist circumference. Events, $n=187$, participants, $n=2,569$. Panel adapted with permission from Hanley et al. [67]. b Bar graph of 6.9 year risk of CVD in 3,606 participants with the metabolic syndrome (MS) and with individual components of the metabolic syndrome, i.e. dyslipidaemia (Dyslip), hypertension (HTN), obesity (OB) and insulin resistance (IR, highest HOMA quartile) in the Botnia Study. Panel adapted with permission from Isomaa et al. [68] 
Thus, a defect in insulin signalling, not only impairs glucose utilisation, but causes hypertension and accelerated atherosclerosis.

Insulin is a potent growth factor [20, 26, 27, 91, 92], whose growth-promoting effects are mediated via the mitogen-activated protein (MAP) kinase pathway [93]. After the interaction between IRS-1 and SHC, extracellular regulated kinase (ERK) is activated [77, 94], translocates into the nucleus and catalyses phosphorylation of transcription factors that promote cell growth, cell proliferation and cell differentiation [77]. Thus, this pathway plays an important role in atherogenesis. MAP kinase blockade prevents stimulation of insulin's growth-promoting effects, but has no effect on the metabolic actions of insulin $[95,96]$. Insulin resistance in the PI-3 kinase (metabolic) pathway with intact MAP kinase signalling activates multiple inflammatory pathways, including inhibitor $\mathrm{k} \beta(\mathrm{IkB}) /$ nuclear factor $\mathrm{k} \beta(\mathrm{NFkB})$ [97] and c-Jun N-terminal kinase [98], which also cause insulin resistance. Not surprisingly, sustained physiological

a

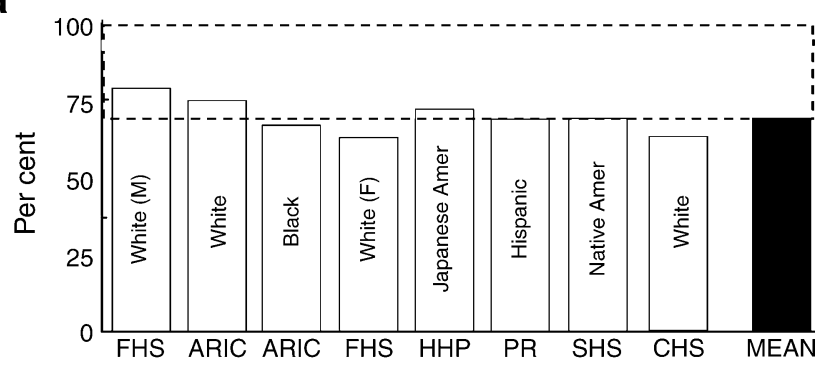

b

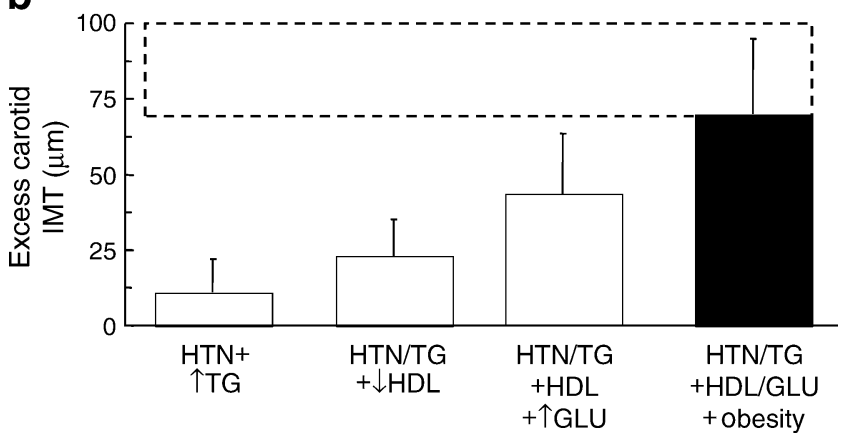

Fig. 3 a Predictive value (\%) of CVD using the Framingham risk engine in Framingham Heart Study (FHS), the Atherosclerosis Risk in Community Study (ARIC), the Honolulu Heart Program (HHP), the Puerto Rico Heart Health Program (PR), the Strong Heart Study (SHS) and the Cardiovascular Health Study (CHS). On mean, the Framingham Risk engine predicts only $69 \%$ of the risk of a future cardiovascular event. Panel adapted with permission from D'Agostino et al. [74]. b Excess carotid intima-media thickness (IMT) in relation to the individual components of the insulin resistance (metabolic) syndrome as listed. Amer, American; HTN, hypertension; F, female; M, male; TG, triacylglycerol; GLU, glucose. Fields in dotted lines, unexplained risk (a $31 \%$; b, 30\%). Panel adapted with permission from Goldsen et al. [76]

\section{a}

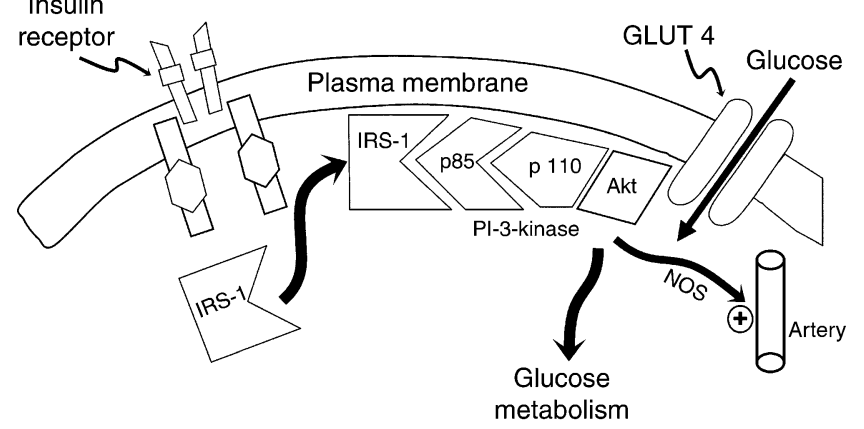

b

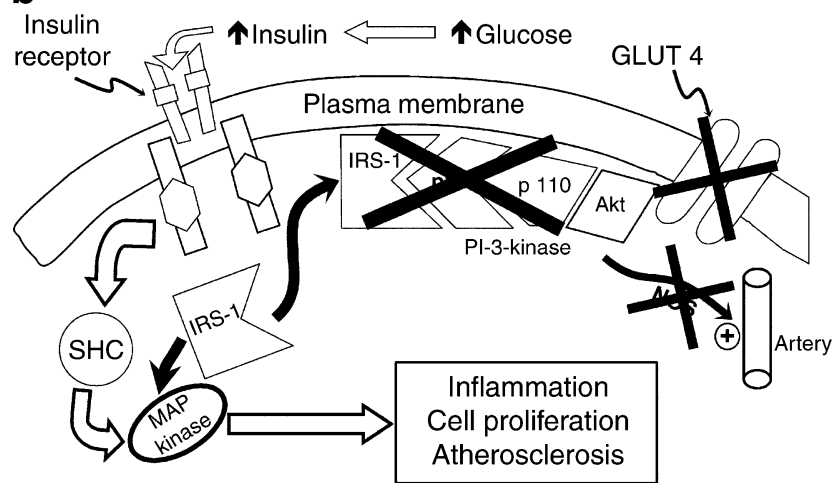

Fig. 4 a Insulin signal transduction system in individuals with normal glucose tolerance (see text for a detailed discussion). NOS, nitric oxide synthase. b In type 2 diabetic participants insulin signalling is impaired at the level of IRS-1 leading to decreased glucose transport/ phosphorylation/metabolism and impaired nitric oxide synthase activation/endothelial function. At the same time, insulin signalling through the MAP kinase pathway is normally sensitive to insulin. The compensatory hyperinsulinaemia (due to insulin resistance in the IRS1/PI-3 kinase pathway) results in excessive stimulation of this pathway, which is involved in inflammation, cell proliferation and atherogenesis (see text for a detailed discussion). SHC, Src homology collagen. Reproduced from DeFronzo [1]

hyperinsulinaemia activates multiple genes involved in inflammation [27].

Insulin receptor defects in type 2 diabetes Some studies $[44,78,99]$ have demonstrated decreased insulin binding to monocytes and adipocytes in type 2 diabetic patients. However, in muscle and liver, insulin binding to solubilised insulin receptors is normal in obese normal glucose-tolerant and lean type 2 diabetic participants [100].

Insulin receptor tyrosine kinase activity In normal-weight and obese diabetic patients, insulin-stimulated insulin receptor tyrosine kinase activity was reduced and could not be explained by decreased insulin receptor number/ binding [101]. Normalisation of fasting plasma glucose with weight loss corrected the defect in insulin receptor tyrosine kinase [102], indicating that the defect is acquired. 
Insulin signalling (IRS-1 and PI-3 kinase) defects As indicated in Fig. 4b, we have shown that in skeletal muscle of lean individuals with normal glucose tolerance, physiological hyperinsulinaemia increases insulin receptor and IRS-1 tyrosine phosphorylation by $150 \%$ to $200 \%$ [94, 103]. In obese non-diabetic participants, activation of these two insulin signalling events in muscle was reduced, while in type 2 diabetic individuals insulin had no significant stimulatory effect [94]. Association of PI-3 kinase with IRS-1/IRS-2 was greatly reduced in obese non-diabetic and type 2 diabetic participants and correlated closely with impaired muscle glycogen synthase activity and with in vivo insulin-stimulated glucose disposal [94].

MAP kinase signalling Our studies in human skeletal muscle [94] (Fig. 4b) were the first to demonstrate that in insulin-resistant type 2 diabetic and obese non-diabetic individuals the profound insulin resistance in the PI-3 kinase pathway contrasts with the normal stimulatory effect of insulin on the MAP kinase pathway (MAP kinase kinase 1 activity and ERK1/2 phosphorylation/activity) [94]. Maintained insulin stimulation of the MAP kinase pathway, with persistent insulin resistance in the PI-3 kinase pathway, represents an important pathogenic mechanism for development of CVD in insulin-resistant states (see subsequent discussion).

\section{Molecular link between insulin resistance and atherosclerosis}

Our studies in man demonstrated that impaired IRS-1 tyrosine phosphorylation/PI-3 kinase activation in lean type 2 diabetic and obese non-diabetic participants causes a profound defect in glucose transport/phosphorylation and glycogen synthesis (Fig. 4b) [104, 105]. Because nitric oxide synthase is activated by the same PI-3 kinase pathway, nitric oxide production is impaired [106, 107], resulting in endothelial dysfunction [108-110] and accelerated atherosclerosis [110-113]. This pathogenic sequence establishes the molecular basis linking insulin resistance, inflammation and accelerated atherosclerosis in people with type 2 diabetes mellitus and may help account for the missing 30\% CVD risk that cannot be explained by circulating cardiovascular risk factors [74, 76] (Fig. 4b). This pathogenic sequence also explains why insulin resistance is a strong predictor of CVD [67-73].

Once the insulin signalling defect becomes established, it initiates a reverberating negative feedback cycle. Impaired glucose utilisation causes hyperglycaemia, which stimulates insulin secretion (Fig. 4b). Because the IRS-1/PI-3 kinase pathway is defective, the MAP kinase pathway is excessively stimulated since it is normally sensitive to insulin. Increased IRS-1 serine phosphorylation, induced by metabolic/inflammatory abnormalities present in the diabetic state (reviewed by Draznin [114]), further impairs insulin signalling through the PI-3 kinase pathway [115, 116]. In diabetic and obese patients, continued MAP kinase pathway stimulation [94] causes vascular smooth muscle proliferation, increased collagen formation and excessive production of growth factors/inflammatory cytokines, contributing to accelerated atherosclerosis. The same insulin signalling defects that we have demonstrated in skeletal muscle of type 2 diabetic patients have been demonstrated in arterial vascular smooth muscle cells (VSMC) in animal models of diabetes and in humans [92, 117, 118].

Draznin and colleagues $[93,114]$ have provided additional evidence for this 'dual insulin signalling hypothesis'. In cultured VSMCs and endothelial cells treated with PI-3 kinase inhibitors, insulin cannot activate nitric oxide synthase to generate nitric oxide and these cells are no longer protected from the detrimental effects of vascular endothelial growth factor, platelet-derived growth factor (PDGF) and other inflammatory peptides. Insulin continues to stimulate VSMC proliferation/migration even though the PI-3 kinase pathway has been inhibited and increases prenylated Ras (rat sarcoma) and Rho (Ras related homologue), leading to augmented VSMC response to the growth-promoting effects of IGF-1, epidermal growth factor, PDGF and angiotensin II. These effects are enhanced when PI-3 kinase is inhibited [119, 120]. The sensitising effect of VSMCs to angiotensin II is of particular importance, since hyperinsulinaemia doubles the ability of angiotensin II to transactivate NF-kB [120], a powerful nuclear transcription factor that activates multiple inflammatory pathways involved in atherogenesis [121, 122] and causes IRS-1 serine phosphorylation, which inhibits insulin signalling [123]. Angiotensin II also serine phosphorylates IRS-1 in aortic smooth muscle and skeletal muscle cells [124]. This provides a pathophysiological link between insulin resistance, atherogenesis and essential hypertension.

\section{Genetic vs acquired defects in insulin signal transduction}

To examine whether the insulin signalling defect is genetic or acquired, we studied lean normal glucose-tolerant offspring of two diabetic parents [65]. These offspring are severely insulin-resistant $[65,103]$ and at high risk of developing diabetes. Insulin-stimulated glucose disposal was markedly reduced despite increased insulin receptor 
tyrosine phosphorylation [103]. Basal and insulinstimulated IRS-1 tyrosine phosphorylation/PI-3 kinase activity were markedly reduced. From these observations five points ensue: (1) early in the natural history of type 2 diabetes insulin receptor activation is normal (Fig. 4b); (2) the rate-limiting step for insulin signalling resides at IRS-1; (3) molecular abnormalities responsible for insulin resistance are present long before onset of overt diabetes or impaired glucose tolerance; (4) insulin normally augments MAP kinase, but not PI-3 kinase, demonstrating dissociation between regulation of PI-3 kinase and MAP kinase pathways; and (5) tissues of offspring with normal glucose tolerance are being 'incubated' in a 'sea' of molecular insulin resistance and atherogenicity from an early age, explaining in part why clinically evident CVD is present in 15 to $20 \%$ of individuals at initial diagnosis [125] and why insulin resistance and CVD are closely linked [19, 20, 44, 67-72]. Only thiazolidinediones simultaneously augment the PI-3 kinase (metabolic) pathway while inhibiting the MAP kinase (atherogenic) pathway [126, 127]. Thiazolidinediones also enhance nitric oxide synthase activity, increasing nitric oxide production [128-130]; they also reduce highsensitivity C-reactive protein levels and improve multiple cardiovascular risk factors in type 2 diabetic participants [131].

\section{Lipotoxicity, insulin resistance and atherosclerotic CVD}

The term 'lipotoxicity' was coined by Unger to describe the deleterious effect of tissue fat accumulation on glucose metabolism [132]. However, lipotoxicity has assumed added significance (see textbox: Lipotoxicity). Experimental NEFA elevation to reproduce levels in type 2 diabetes causes severe muscle/liver insulin resistance [133-135] and inhibits insulin secretion [136], reproducing the three basic core defects of type 2 diabetes. Elevated plasma NEFA impair glucose oxidation/glycogen synthesis [133] and decrease glucose transport/phosphorylation [104, 135]. Most importantly, lipid infusion to increase plasma NEFA levels in participants with normal glucose tolerance caused a dose-response inhibition of insulin receptor/IRS-1 tyrosine phosphorylation and PI-kinase activity, which correlate closely with reduced insulin-stimulated glucose disposal [137].
Magnetic resonance spectroscopic studies have demonstrated that intramyocellular and intrahepatic fat accumulation are closely associated with organ-specific insulin resistance [138-141]. Intracellular toxic metabolites of triacylglycerol and NEFA metabolism (fatty acyl CoA, diacylglycerol, ceramides) cause severe insulin resistance by impairing insulin signalling and multiple intracellular steps of glucose metabolism [133, 137, 142]. To examine the causality of this association, we treated type 2 diabetic patients with acipimox, an inhibitor of lipolysis. The decline in plasma NEFA (563 to $230 \mathrm{mmol} / \mathrm{l}$ ) was associated with decreased muscle long-chain fatty acyl CoA [143], which correlated closely with enhanced insulin-stimulated muscle glucose uptake (Fig. 5). The deleterious effect of increased intracellular fat on insulin sensitivity is supported by the work of Kim et al. [144], who overexpressed lipoprotein lipase in muscle or liver in mice. In muscle this caused a marked increase in fat content, severe insulin resistance and impaired PI-3 kinase activity, without affecting hepatic insulin sensitivity. Lipoprotein lipase overexpression in liver increased hepatic fat content, induced severe hepatic insulin resistance and impaired hepatic insulin signalling, but had no effect on muscle [144]. Long-chain fatty acyl CoAs cause IRS-1 serine phosphorylation, thereby inhibiting the PI 3 kinase pathway $[145,146]$.

In animals [147] and humans [148], plasma NEFA elevation by lipid infusion also increased intramyocellular diacylglycerol, a potent activator of protein kinase C (PKC) isoforms, which inhibit insulin signalling through serine phosphorylation of IRS-1 [149]. Muscle [150] and plasma [151] ceramide levels are also increased in obese and type 2 diabetic individuals, correlating closely with severity of insulin resistance.

In summary, much evidence supports the notion that increased plasma NEFA/intramyocellular levels of toxic lipid metabolites (long-chain fatty acyl CoAs, diacylglycerol, ceramides) play a role in the pathogenesis of muscle/ liver insulin resistance.

\section{NEFA, inflammation and atherosclerosis: the neglected lipid}

Type 2 diabetes and obesity are characterised by low-grade, chronic inflammation [152-154], which could contribute to

\begin{tabular}{|ll|}
\hline Lipotoxicity & Reversal of lipotoxicity with thiazolidinediones \\
- Elevated plasma NEFA & - Decreases plasma NEFA \\
- Increased tissue fat content & - Decreases muscle long-chain fatty acyl CoA \\
- Altered fat topography & - Redistributes fat \\
- Adiposopathy & - Reverses adiposopathy \\
\hline
\end{tabular}


a
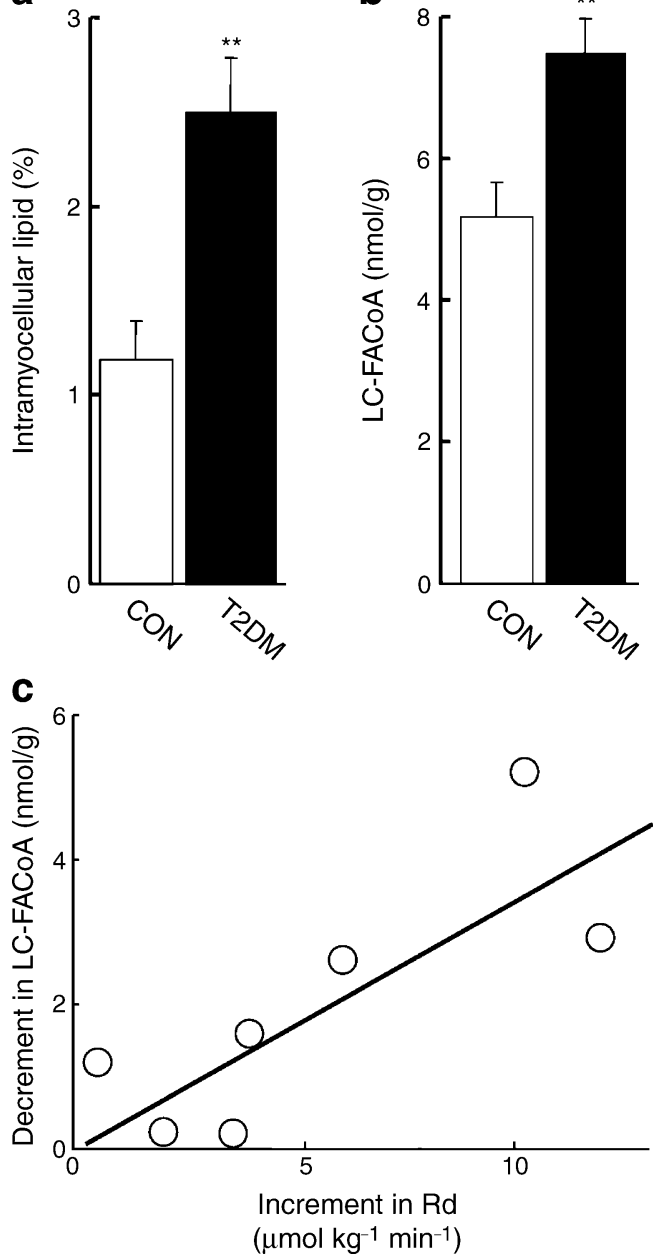

Fig. 5 a Intramyocellular lipid content (measured by magnetic resonance spectroscopy) and (b) muscle long-chain fatty acyl CoA (LC-FACoA) content in control (CON) and type 2 diabetic (T2DM) participants. ${ }^{* *} p<0.01$ for T2DM vs CON. c Relationship between the increment in insulin-stimulated rate of glucose disposal (Rd) and decrement in muscle LC-FACoA content in type 2 diabetic participants after treatment with acipimox. $p<0.01 ; r=0.74$. Figure adapted with permission from Bajaj et al. [143]

accelerated atherosclerosis. Increased activity of $\mathrm{IkB} / \mathrm{NFkB}$ provides a molecular mechanism responsible for inflammation and insulin resistance in type 2 diabetes mellitus [91, $148,152,155]$. Under basal conditions, NFkB is associated with IkB in the cytoplasm (Fig. 6). Upon activation by inflammatory factors, including fatty acyl CoAs, IkB kinase phosphorylates IkB, causing $\mathrm{IkB}$ polyubiquitination and degradation. The free NFkB translocates to the nucleus, where it binds to target genes, stimulating inflammatory mediators (TNF $\alpha$, IL-1B, IL-6, PKC) involved in atherogenesis $[152,156,157]$. TNF $\alpha$, IL-6 and PKC, as well as IK kinase, cause serine phosphorylation of IRS-1, inhibiting insulin signalling and causing insulin resistance $[123,158]$.

Skeletal muscle IkB content is decreased in type 2 diabetic patients [159], indicative of increased NFkB activity. We have confirmed this by demonstrating increased NF-kB p50-p65 DNA binding activity in type 2 diabetic and obese individuals (P Tantiwong, K Shammugasumdaran, A Monroy, S Ghosh, E Cersosimo, A Sriwijitkamol, RA DeFronzo, S Mohan, $\mathrm{N}$ Musi, unpublished results). Reduced IkB and increased NFkB p50-p65 binding activity were strongly correlated with reduced insulin sensitivity.

Multiple stimuli [152], including lipids, activate IkB kinase/NFkB, causing insulin resistance in cultured myocytes [160] and muscle from rodents [155, 161] and humans [162]. In human myocytes, palmitate enhances NFkB activity and increases IL6 mRNA, a downstream gene regulated by NFkB. Transfection of myocytes with an adenovirus-IkB super repressor mutant blocked the augmentation of NFkB activity and of IL 6 mRNA expression by palmitate [162].

Circulating NEFA also cause inflammation and insulin resistance by directly activating plasma membrane receptors, such as toll-like receptor 4 [162] (Fig. 7). In muscle of obese and type 2 diabetic individuals, toll-like receptor 4 $\mathrm{mRNA} /$ protein content is increased and correlates closely with HOMA-IR [162] and IkB/NFkB activation, providing another pathway via which NEFA incite inflammation and promote atherogenesis.

NEFA also stimulate formation of collagen, an integral component of the atherosclerotic plaque [163, 164]. Physiological NEFA elevation in participants with normal glucose tolerance increases mRNA expression of collagen, fibronectin and lumican, as well as connective tissue growth factor [134], a member of the CCN gene family, which mediates fibrotic responses [163]. Increased connective tissue growth factor levels are a characteristic finding in complicated atherosclerotic plaques and induce mononuclear cell chemotaxis [164].

Plasma NEFA exert profound effects on endothelial function. Insulin-stimulated blood flow is mediated via nitric oxide [86] and is impaired in obese and type 2 diabetic individuals [108, 165]. Experimental plasma NEFA elevation in participants with normal glucose tolerance reduced endothelium-dependent blood flow, without altering endothelium-independent blood flow [166]. Endothelial dysfunction is associated with accelerated atherosclerosis and insulin resistance $[110,111]$, providing another mechanism via which NEFA promote CVD in type 2 diabetes mellitus.

\section{Adiposopathy}

'Adiposopathy' is another form of lipotoxicity [131]. Fat cells produce adipocytokines, which travel to distant sites (muscle, liver, arterial tissue) where they exert deleterious 
Fig. 6 Relationship between intracellular fatty acyl CoA levels, $\mathrm{IkB} / \mathrm{NFkB}$ and the insulin signal transduction pathway (see text for a detailed discussion). iNOS, inducible nitric oxide synthase

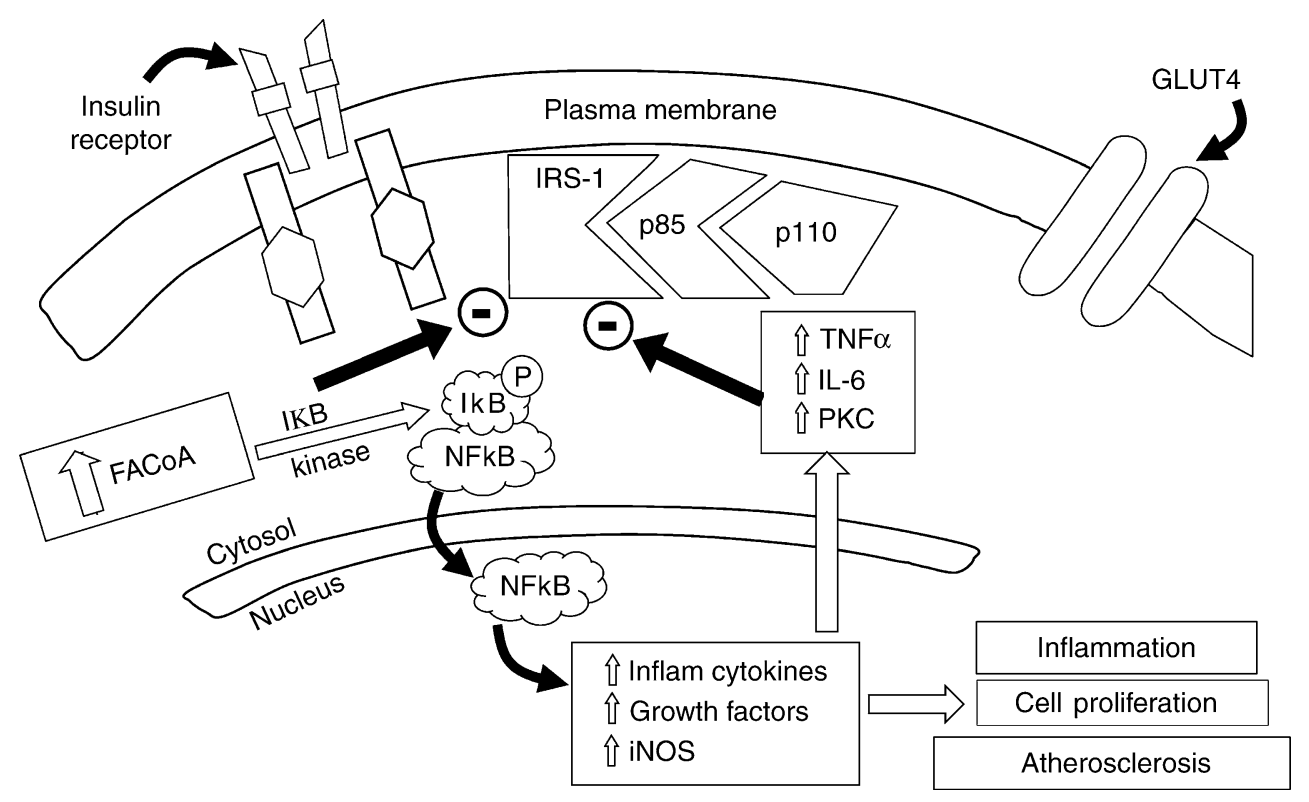

effects on metabolism and vascular function. Adipose tissue of obese and type 2 diabetic individuals is infiltrated by mononuclear cells and is in a state of chronic inflammation [167]. The adipocytes and infiltrated macrophages secrete proinflammatory/prothrombotic cytokines (TNF $\alpha$, resistin, IL-6, plasminogen activator inhibitor-1, angiotensinogen) that promote atherogenesis and cause insulin resistance (reviewed by Bays et al. [131]). Adipocytes also underproduce adiponectin, a potent insulin-sensitising, antiatherogenic cytokine [131].

\section{Fat topography}

Accumulation of fat within the intraabdominal cavity, i.e. visceral fat (Fig. 8), is associated with insulin resistance and CVD [131, 168, 169]. Although the mechanism(s) for this association remain(s) unclear, visceral obesity is part of the insulin resistance (metabolic) syndrome [38-40]; however, the individual components of the insulin resistance syndrome, not the increase in visceral fat, may account for the increased incidence of CVD.

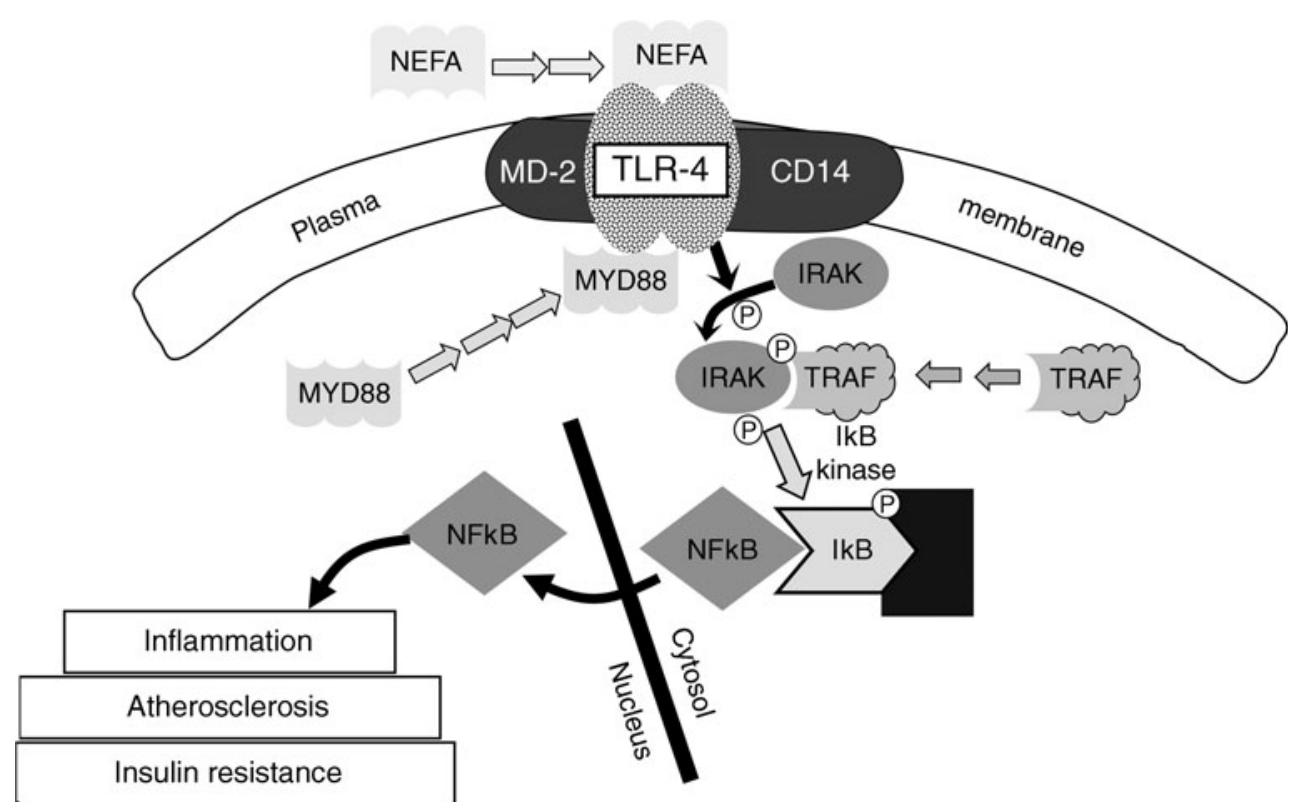

Fig. 7 Schematic representation of the toll-like receptor 4 (TLR-4) pathway and its activation by NEFA. Dissociation of NFkB from IkB allows it to diffuse into the nucleus where it can turn on genes associated with inflammation, atherosclerosis and insulin resistance (see text for a detailed discussion). CD14, cluster of differentiation 14; IRAK, interleukin-1 receptor associated kinase, MD-2, myb regulated gene; MYD88, myeloid differentiation primary response gene; TRAF, TNFa receptor associated factor 


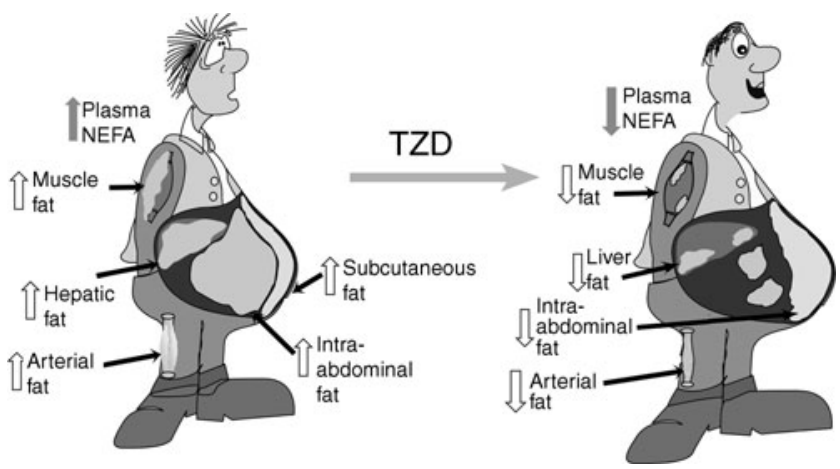

Fig. 8 Fat topography in type 2 diabetes and effect of thiazolidine-diones (TZD) (see text for a detailed discussion)

\section{What therapeutic interventions reverse lipotoxicity?}

Tissue fat overload is explained by: (1) excessive energy intake; (2) increased lipolysis in insulin-resistant adipocytes, leading to increased plasma NEFA and enhanced influx into muscle/liver; and (3) decreased fat oxidation. Weight loss (energy-intake restriction) has proven effective in reducing total body fat content [170]. Glucagon-like peptide-1 analogues are potent appetite suppressants and effectively promote weight loss [171].

Thiazolidinediones exert the following unique actions that ameliorate lipotoxicity (Textbox 3): (1) decrease plasma NEFA by inhibition of lipolysis; (2) reduction of muscle long-chain fatty acyl CoA levels; (3) redistribution of fat within the body; and (4) amelioration of adiposopathy.

Thiazolidinediones, insulin sensitivity and NEFA metabolism Thiazolidinediones are potent insulin sensitisers in muscle and liver [126, 127, 140, 141, 172, 173] and improve sensitivity to the antilipolytic effect of insulin, decreasing basal NEFA turnover/plasma NEFA [172]. Thiazolidinediones also improve hepatic insulin sensitivity, leading to decreased basal hepatic glucose production and enhanced hepatic glucose production suppression by insulin [140, 172-174]. Reduced plasma NEFA levels correlate closely with improved insulin-stimulated muscle glucose disposal and decreased hepatic glucose production.

In type 2 diabetic patients, impaired insulin-stimulated IRS-1 tyrosine phosphorylation and PI 3 kinase activity [94] (Fig. 9) are improved by rosiglitazone [126], with enhanced insulin signalling correlating closely with reduced plasma NEFA. Similarly, pioglitazone increases insulinstimulated glucose disposal by $35 \%$ in association with reduced fasting NEFA, muscle fat content and fatty acyl CoAs [127, 173] (Fig. 5). These results provide strong evidence that thiazolidinediones improve muscle insulin sensitivity via reversal of lipotoxicity.
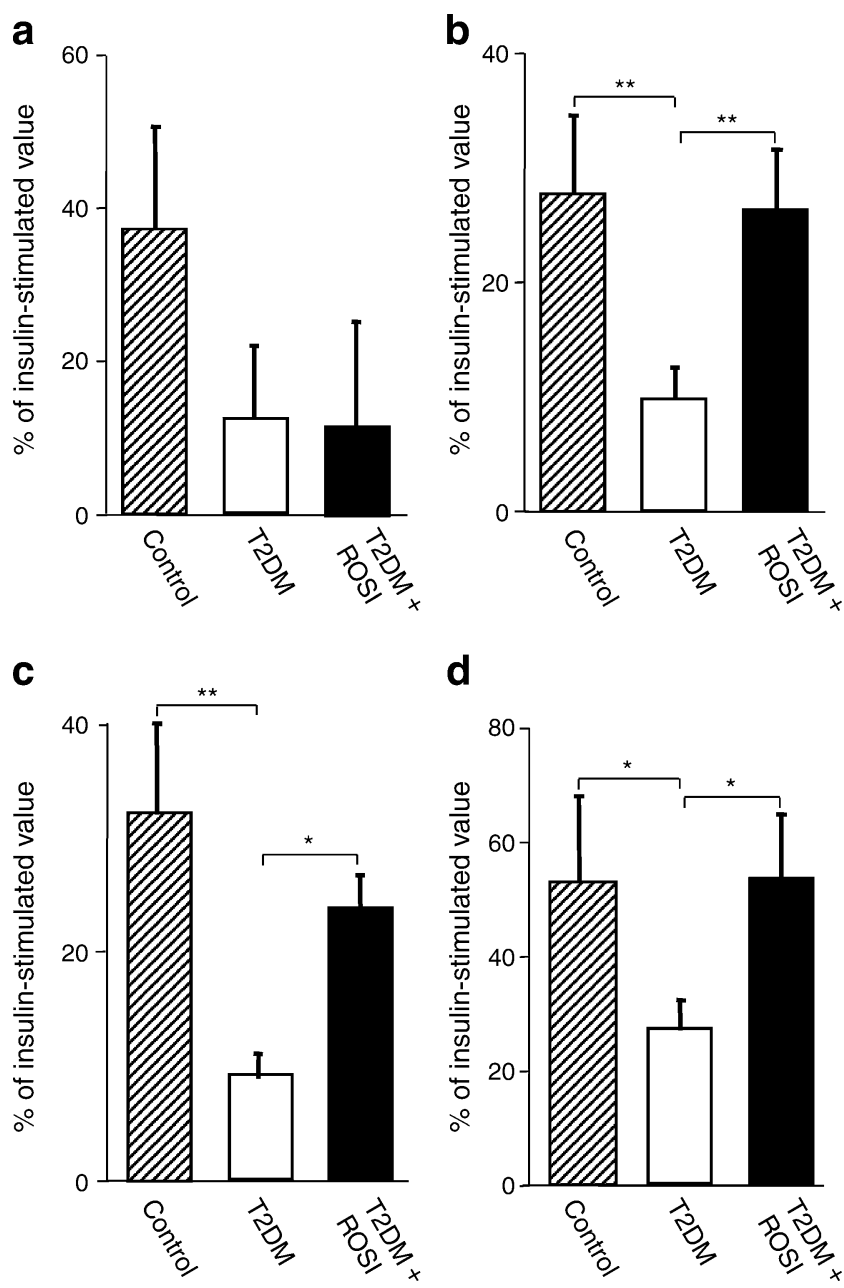

Fig. 9 Rosiglitazone (ROSI) treatment of type 2 diabetic patients (T2DM) for 4 months markedly augmented insulin signalling through the IRS-1/PI-3 kinase pathway without altering (a) insulin receptor tyrosine phosphorylation, (b) IRS-1 tyrosine phosphorylation, (c) association of p85 subunit of PI-3 kinase with IRS-1 and (d) association of PI-3 kinase with IRS-1. ${ }^{*} p<0.05 ;{ }^{* *} p<0.01$. Figure adapted with permission from Miyazaki et al. [126]

Mitochondrial dysfunction, lipotoxicity and thiazolidinediones Impaired ATP synthesis and mitochondrial dysfunction have been demonstrated in insulin-resistant states including ageing, offspring of diabetic parents, obesity and type 2 diabetes mellitus [175-179]. Using ${ }^{31} \mathrm{P}$ nuclear magnetic resonance spectroscopy, Petersen et al. [176] have shown that decreased ATP synthesis is associated with increased intramyocellular fat. In isolated mitochondria from obese and type 2 diabetic individuals, we have demonstrated that ATP synthesis is reduced $[179,180]$ and correlates closely with decreased insulin-stimulated glucose disposal and increased fasting plasma NEFA. To examine whether fatty acid metabolites directly inhibit mitochondrial function, we incubated mitochondria from participants with normal glucose tolerance with palmitoyl carnitine [181]. At concentrations $<2 \mu \mathrm{mol} / 1$, palmitoyl carnitine stimulated ATP 
synthesis, while at concentrations $>2 \mu \mathrm{mol} / 1$ it progressively decreased ATP synthesis and inner mitochondrial membrane potential, which provides the voltage gradient driving electron transport.

Type 2 diabetic individuals and insulin-resistant offspring with normal glucose tolerance have reduced expression of multiple nuclear genes that encode enzymes involved in oxidative metabolism, including peroxisome proliferatoractivated receptor (PPAR) $\gamma$ coactivator (PGC-1) [182], the master regulator of mitochondrial biogenesis [183]. A twofold increase of plasma NEFA in participants with normal glucose tolerance reduced muscle expression of PGC-1 and multiple mitochondrial genes to levels observed in diabetic individuals [134], providing evidence of 'mitochondrial lipotoxicity'. Treatment of type 2 diabetic patients with pioglitazone upregulated $P G C-1 \alpha$ (also known as $P P A R G C 1 A$ ) and PGC-1 $\beta$ (also known as PPARGC1b) mRNA expression in association with increased expression of pyruvate dehydrogenase alpha 1 (PHDA1) and other mitochondrial oxidative phosphorylation genes [175] (Fig. 10), ameliorating 'mitochondrial lipotoxicity'.

Pioglitazone also ameliorates lipotoxicity via effects mediated through adiponectin and adiponectin receptor (Fig. 11). Hypoadiponectinaemia is characteristic of type 2 diabetes. Thiazolidinediones increase plasma adiponectin levels to or above those in non-diabetic patients [131, 173]. Adiponectin is a potent insulin sensitiser in muscle and liver [184] and exerts multiple anti-atherogenic effects $[185,186]$. In type 2 diabetic patients and insulin-resistant offspring with normal glucose tolerance, adiponectin receptor 1 and 2 expression is reduced [187]. Pioglitazone treatment increases expression of muscle adiponectin receptors 1 and 2 and AMP kinase [188]. Similar effects have been demonstrated in cultured human myocytes and do not require PPAR $\gamma$ stimulation [188]. Pioglitazone also upregulated acetyl-CoA carboxylase and carnitine palmitoyl transferase expression/activity, leading to the postulate (Fig. 11) that pioglitazone increases plasma adiponectin levels and expression of adiponectin receptors 1 and 2, stimulating AMP kinase and acetyl-CoA carboxylase activity, with resultant inhibition of malonyl CoA. This augments carnitine palmityol transferase I activity and enhances NEFA flux into mitochondria, where they undergo beta oxidation. The result is a decrease in intramyocellular fatty acyl CoA levels, leading to improved muscle insulin signalling/insulin sensitivity.

Thiazolidinediones and fat topography: clinical implications Thiazolidinediones redistribute body fat by reducing visceral and increasing subcutaneous fat $[189,190]$ (Fig. 8). They also reduce muscle fatty acyl CoA, leading to improved insulin sensitivity and glycaemic control [126, 127, 140, 141, 172, 173, 176]. Thiazolidinediones also reduce liver fat and are effective in treating non-alcoholic steatohepatitis [139, 191]. In a randomised, placebo controlled study of 55 participants with type 2 diabetes/ impaired glucose tolerance and biopsy-proven nonalcoholic steatohepatitis, pioglitazone reduced liver fat by
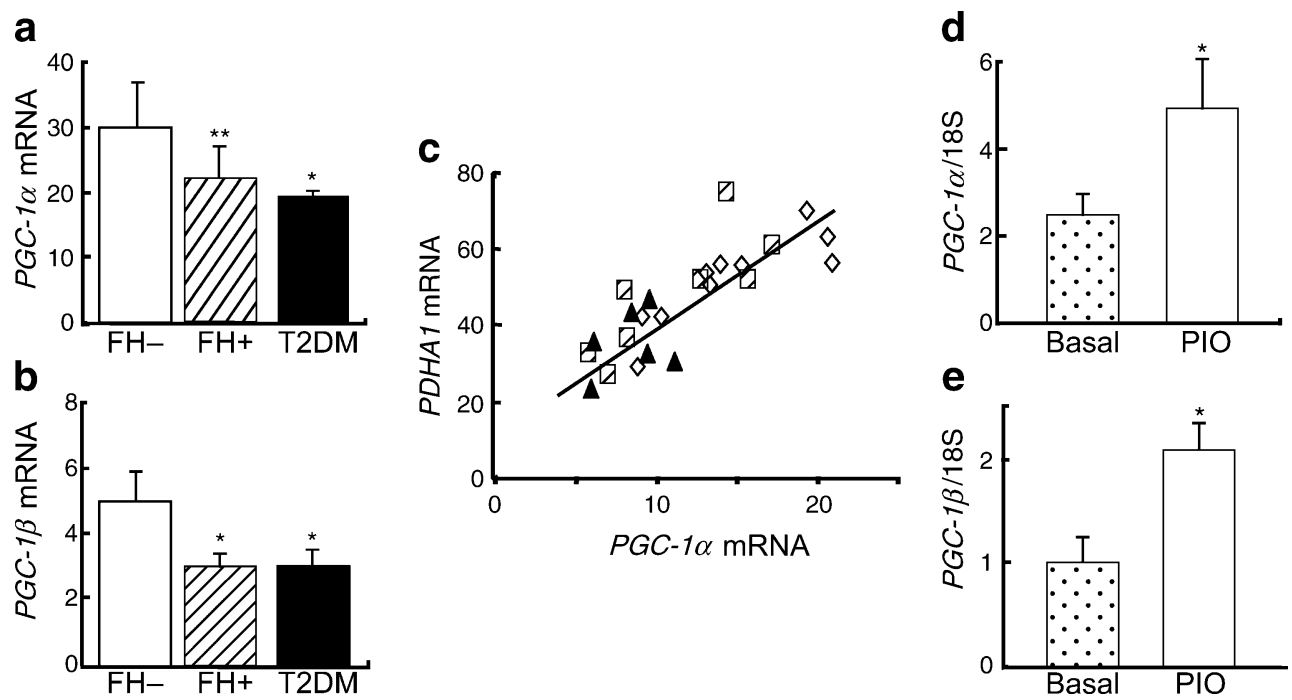

Fig. $10 P G C-1 \alpha$ and $P G C-1 \beta$ expression in muscle of $(\mathbf{a}, \mathbf{b})$ individuals with normal-glucose-tolerance and without family history $(\mathrm{FH}-)$ of diabetes, insulin-resistant normal-glucose-tolerant offspring of two type 2 diabetic parents $(\mathrm{FH}+)$ and participants with type 2 diabetes mellitus (T2DM). c A strong linear relationship exists between $P G C-1 \alpha$ mRNA and PDHA1 mRNA, and the expression of other mitochondrial genes (not shown) involved in oxidative phos- phorylation. White diamonds, FH-; black triangles, type 2 diabetes mellitus; hatched squares, $\mathrm{FH}+$. d, e Pioglitazone (PIO) treatment of type 2 diabetic patients significantly increased the expression of $P G C$ $1 \alpha$ and $P G C-1 \beta$ mRNA in muscle. $* p<0.05$ for $\mathrm{FH}+\mathrm{vs} \mathrm{FH}-; * * p<$ 0.01 for $\mathrm{FH}+$ and $\mathrm{T} 2 \mathrm{DM}$ vs $\mathrm{FH}-$, and $(\mathbf{d}, \mathbf{e}){ }^{*} p<0.05$ for PIO vs Basal. Figure adapted with permission from Patti et al. [182] and Coletta et al. [175] 
Fig. 11 Amelioration of lipotoxicity by action of pioglitazone in increasing the plasma adiponectin concentration and levels of adiponectin receptors (ADIPOR) 1 and 2. See text for a detailed discussion. ACC, acetyl CoA carboxylase; CPT-1, carnitine palmitoyl transferase1; CREB, cAMP response element binding; DAG, diacylglycerol; MEF2C, myocyte enhancer factor 2C. Figure adapted with permission from Civitarese et al. [187] and Coletta et al. [175]

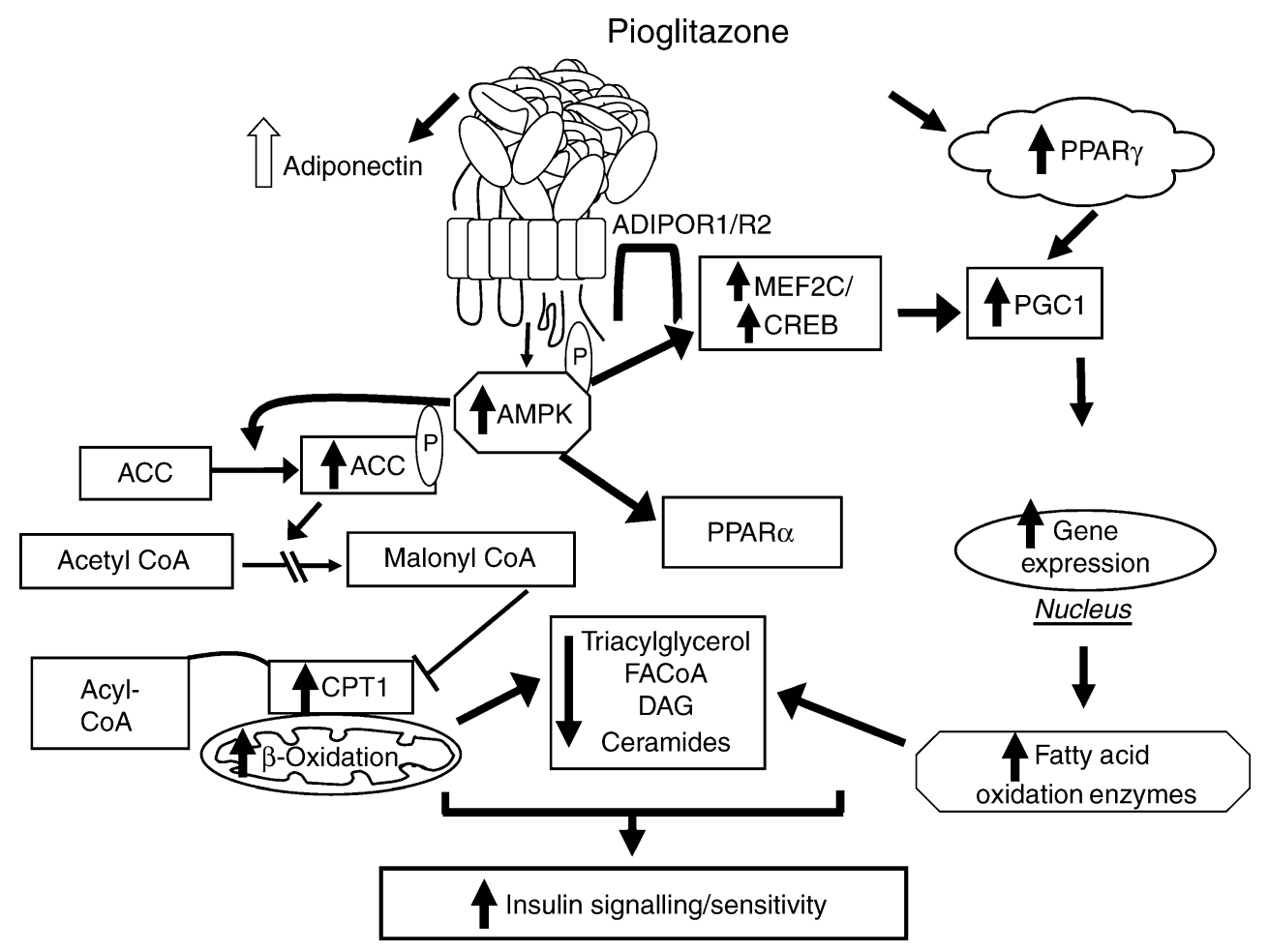

54\% $(p<0.001)$, normalised alanine aminotransferase and aspartate aminotransferase, and reduced hepatic inflammation, ballooning necrosis and fibrosis [139].

Thiazolidinediones preserve beta cell function in type 2 diabetic patients [192]. Eight double-blind, placebo/active comparator-controlled studies demonstrate that thiazolidinediones have a durable effect in reducing $\mathrm{HbA}_{1 \mathrm{c}}$ (reviewed by DeFronzo [1]) because of a beta cell protective effect. Five studies in participants with impaired glucose tolerance document that thiazolidinediones markedly reduced conversion to type 2 diabetes, primarily by improving beta cell function (reviewed by DeFronzo [1]). Using the gold standard insulin secretion/insulin resistance (disposition) index, both pioglitazone and rosiglitazone have been shown to improve beta cell function in drug naive and sulfonylurea-treated type 2 diabetic patients [192]. Thiazolidinediones augment beta cell function by multiple mechanisms, including direct effects (increased GLUT2, glucokinase, $P d x$ ) exerted through PPAR $\gamma$ [193], and by reducing intracellular fatty acyl CoA levels [194-196].

Myocardial lipid content is increased in type 2 diabetic individuals [197, 198] and contributes to diastolic dysfunction $[198,199]$. The myocardium in type 2 diabetes is markedly insulin-resistant $[61,198]$. The insulin resistance cannot be explained by coronary artery disease [199] and correlates with increased myocardial fat [198, 200]. Rosiglitazone similarly improved myocardial and skeletal muscle insulin resistance [62]. Although myocardial fat content was not measured in these studies, it is reasonable to hypothesise that thiazolidinediones exert their myocardial insulin sensitising effect, in part by reducing myocardial fat content.

Coronary and carotid arterial disease represent the major cause of mortality in patients with type 2 diabetes [4]. Elevated plasma LDL-cholesterol and triacylglycerol, and reduced HDL-cholesterol all contribute to accelerated atherogenesis in type 2 diabetes. Quantitative lipid analysis of atherosclerotic plaques reveals large amounts of NEFA and fatty acid metabolites [35-37], which can stimulate inflammatory pathways involved in atherogenesis. Pioglitazone reduces plasma triacylglycerol, increases HDL-cholesterol, converts small dense LDL particles to larger more buoyant ones and decreases apolipoprotein B-100 without altering plasma LDL-cholesterol [201, 202]. Thiazolidinediones also markedly reduce plasma NEFA [127, 139, 172], which would be expected to reduce fatty acyl CoAs and other toxic fatty acid metabolites within arterial smooth muscle cells, thus inhibiting atherogenesis. Thiazolidinediones also inhibit release of proinflammatory, prothrombotic, atherogenic adipocytokines from fat tissue [139, 141, 172, 203] and redistribute fat from visceral (atherosclerotic equivalent) to subcutaneous depots [189, 190]. Thus, thiazolidinediones ameliorate all components of the 'lipotoxicity syndrome'. Therefore, one could expect thiazolidinediones to reduce cardiovascular events in type 2 diabetes.

The Prospective Pioglitazone Clinical Trial in Macrovascular Events [204] examined the effect of pioglitazone on cardiovascular outcomes in type 2 diabetes patients with a previous cardiovascular event. Although the primary composite endpoint did not reach statistical significance, a 
beneficial trend (10\% decrease) was observed; the second principal endpoint (time to death, myocardial infarction, stroke) was significantly reduced. Analysis of all doubleblind placebo-controlled pioglitazone trials in the USA demonstrated a significant reduction in cardiovascular events [205]. Consistent with these trials, pioglitazone decreased carotid intima medial thickness [206] and coronary atherosclerotic plaque volume [207].

Weight gain and thiazolidinedione paradox Thiazolidinedione treatment is associated with modest weight gain (1$3 \mathrm{~kg}$ ) that occurs within the first 12 months of treatment. Paradoxically, the greater the weight gain, the greater the reduction in $\mathrm{HbA}_{1 \mathrm{c}}$ and the greater the improvements in insulin sensitivity and beta cell function [173, 189, 192]. This paradox is explained as follows. Thiazolidinediones mobilise fat from muscle, liver and beta cells leading to improved insulin sensitivity and beta cell function. PPAR $\gamma$ receptors are abundant in hypothalamic appetite regulation centres [208]. Thus, thiazolidinediones simultaneously evoke two effects: (1) PPAR $\gamma$ activation in muscle/liver/ adipocytes/beta cells; and (2) stimulation of appetite. The former improves glucose homeostasis, while the latter promotes weight gain. Consequently, increased body weight is a strong predictor of improved glycaemic control $\left(\mathrm{HbA}_{1 \mathrm{c}}\right)$ in type 2 diabetes mellitus [204].

\section{Summary}

Insulin resistance in the PI-3 kinase pathway with normal insulin sensitivity in the MAP kinase pathway plays an important role in accelerated atherogenesis in patients with type 2 diabetes mellitus. Lipotoxicity is a major cause of insulin resistance and impaired beta cell function in type 2 diabetes mellitus and plays a central role in the accelerated CVD. Interventions that mobilise fat out of tissues (restriction of energy intake, thiazolidinediones, glucagonlike peptide-1 analogues) are likely to produce a durable reduction in glycaemia and reduce atherosclerotic cardiovascular events.

\section{Acknowledgement}

Duality of interest R. A. DeFronzo is a speaker for Amylin-Lilly and Takeda, has received grants from Amylin, Lilly, Takeda and Bristol Myers Squibb, and is an Advisory Board member and/or consultant for Amylin, Takeda, Boehringer-Ingelheim, ISIS, Novartis and Roche.

Open Access This article is distributed under the terms of the Creative Commons Attribution Noncommercial License which permits any noncommercial use, distribution, and reproduction in any medium, provided the original author(s) and source are credited.

\section{References}

1. DeFronzo RA (2009) From the triumvirate to the ominous octet: a new paradigm for the treatment of type 2 diabetes mellitus. Diabetes 58:773-795

2. Diabetes Control and Complications Trial Research Group (1993) The effect of intensive treatment of diabetes on the development and progression of long-term complications in insulin-dependent diabetes mellitus. N Engl J Med 329:977-986

3. Stratton LM, Adler AJ, Neil HA et al (2000) Association of glycaemia with macrovascular and microvascular complications of type 2 diabetes (UKPDS 35): prospective observational study. BMJ 321:405-412

4. Morrish NJ, Wang SL, Stevens LK et al (2001) Mortality and causes of death in the WHO multinational study of vascular disease in diabetes. Diabetologia 44(Suppl 2):S14-S21

5. Haffner SM, Lehto S, Ronnemaa T et al (1998) Mortality from coronary heart disease in subjects with type 2 diabetes and in nondiabetic subjects with and without prior myocardial infarction. N Engl J Med 339:229-234

6. Giorda CB, Avogaro A, Maggini M et al (2008) Recurrence of cardiovascular events in patients with type 2 diabetes. Diabetes Care 31:2154-2159

7. Gerstein HC, Miller ME, Byington RP et al (2008) Effects of intensive glucose lowering in type 2 diabetes. N Engl J Med 358:2345-2359

8. Patel A, MacMahon S, Chalmers J et al (2008) Intensive blood glucose control and vascular outcomes in patients with type 2 diabetes. New Engl J Med 358:2560-2725

9. Duckworth W, Abraira C, Mortiz T et al (2009) Glucose control and vascular complications in veterans with type 2 diabetes. $\mathrm{N}$ Engl J Med 360:129-139

10. UK Prospective Diabetes Study (UKPDS) Group (1998) Intensive blood-glucose control with sulphonylureas or insulin compared with conventional treatment and risk of complications in patients with type 2 diabetes (UKPDS 33). Lancet 352:837-853

11. Holman RR, Paul SK, Bethel MA et al (2008) 10-year follow-up of intensive glucose control in type 2 diabetes. N Engl J Med 359:1577-1589

12. Nathan DM, Cleary PA, Backlund JY et al (2005) Intensive diabetes treatment and cardiovascular disease in patients with type I diabetes. N Engl J Med 22:2643-53

13. Henry RR, Gumbiner B, Ditzler T et al (1993) Intensive conventional insulin therapy for type II diabetes. Metabolic effects during a 6-month outpatient trial. Diabetes Care 16:21-31

14. Holman RR, Thorne KI, Farmer AJ et al (2007) Addition of biphasic, prandial, or basal insulin to oral therapy in type 2 diabetes. N Engl J Med 357:1716-1730

15. Calle EE, Thun MJ, Petrelli JM et al (1999) Body-mass index and mortality in a prospective cohort of U.S. adults. New Engl J Med 341:1097-1105

16. Allison DB, Fontaine KR, Manson JE et al (1999) Annual deaths attributable to obesity in the United States. JAMA 282:1530-1538

17. Del Prato S, Leonetti F, Simonson DC et al (1994) Effect of sustained physiologic hyperinsulinemia and hyperglycaemia on insulin secretion and insulin sensitivity in man. Diabetologia 37:1025-1035

18. Iozzo P, Pratipanawatr T, Pijl H et al (2001) Physiological hyperinsulinemia impairs insulin-stimulated glycogen synthase activity and glycogen synthesis. Am J Physiol 280:E712-E719

19. Kashyap SR, DeFronzo RA (2007) The insulin resistance syndrome: physiologic considerations. Diab Vasc Dis Res 4:1319 
20. DeFronzo RA, Ferrannini E (1991) Insulin resistance: a multifaceted syndrome responsible for NIDDM, obesity, hypertension, dyslipidemia, and ASCVD. Diabetes Care Reviews 14:173-194

21. DeFronzo RA (2006) Is insulin resistance atherogenic? Possible mechanisms. Atherosclerosis 7:11-15

22. Koopmans SJ, Kushwaha RS, DeFronzo RA (1999) Chronic physiologic hyperinsulinemia impairs suppression of plasma free fatty acids and increases de novo lipogenesis in conscious normal rats. Metabolism 48:330-337

23. Tobey TA, Greenfield M, Kraemer F et al (1981) Relationship between insulin resistance, insulin secretion, very low density lipoprotein kinetics and plasma triglyceride levels in normotriglyceridemic man. Metabolism 30:165-171

24. Azzout-Marniche D, Becard D, Guichard C et al (2000) Insulin effects on sterol regulatory-element-binding protein-1c (SREBP-1c) transcriptional activity in rat hepatocytes. Biochem J 350:389-393

25. Stout TW (1971) The effect of insulin on the incorporation of (1-C) sodium acetate into the lipids of the rat aorta. Diabetologia 7:367-372

26. King GL, Goodman D, Buzney S et al (1985) Receptors and growth promoting effects of insulin and insulin like growth factors on cells from bovine retinal capillaries and aorta. J Clin Invest 75:1028-1036

27. Coletta D, Balas B, Chavez AO et al (2008) Effect of acute physiological hyperinsulinemia on gene expression in human skeletal muscle in vivo. Am J Physiol Endo Metab 294:E910 E917

28. Nakao J, Ito H, Kanayasu T et al (1985) Stimulatory effect of insulin on aortic smooth muscle cell migration induced by 12-Lhydroxy-5, 8, 10, 14-eicosatetraenoic acid and its modulation by elevated extracellular glucose levels. Diabetes 34:185-191

29. Pfeifle B, Ditschuneit H (1981) Effect of insulin on the growth of cultured arterial smooth muscle cells. Diabetologia 20:155-158

30. Cruz AB, Amatuzio DS, Grande F et al (1961) Effect of intraarterial insulin on tissue cholesterol and fatty acids in alloxandiabetic dogs. Circ Res 9:39-43

31. Duff GL, McMillan GC (1949) The effect of alloxan diabetes on experimental cholesterol atherosclerosis in the rabbit. J Exp Med 89:611-630

32. Stamler J, Pick R, Katz LN (1960) Effect of insulin in the induction and regression of atherosclerosis in the chick. Circ Res 8:572-526

33. Meehan WP, Buchanan TA, Hsueh W (1994) Chronic insulin administration elevates blood pressure in rats. Hypertension 23:1012-1017

34. Wang L, Sapuri-Butin AR, Aung HH et al (2008) Triglyceriderich lipoprotein lipolysis increases aggregation of endothelial membrane microdomains and produces reactive oxygen species. Am J Physiol Heart Circ Physiol 295:H237-H244

35. Felton CV, Crook D, Davies MJ et al (1997) Relation of plaque lipid composition and morphology to the stability of human aortic plaques. Arterio Throm Vasc Biol 17:1337-1345

36. Felton CV, Crook D, Davies MJ et al (1994) Dietary polyunsaturated fatty acids and composition of human aortic plaques. Lancet 344:1195-1196

37. Stachowska E, Doxegowska B, Chlubek D et al (2004) Dietary trans fatty acids and composition of human atheromatous plaques. Eur J Nutr 43:313-318

38. Third report of the National Cholesterol Education Program (NCEP) (2002) Expert panel on detection, evaluation, and treatment of high blood cholesterol in adults (Adult Treatment Panel III) final report. Circulation 106:3143-3421

39. Miranda PJ, DeFronzo RA, Califf RM et al (2005) The metabolic syndrome: evaluation of pathologic and therapeutic outcomes. Am Heart J 149:20-45
40. Reaven GM (1988) Banting lecture. Role of insulin resistance in human disease. Diabetes 37:1594-1607

41. DeFronzo RA (1988) Lilly lecture. The triumvirate: beta cell, muscle, liver. A collusion responsible for NIDDM. Diabetes 37:667-687

42. DeFronzo RA, Gunnarsson R, Bjorkman O et al (1985) Effects of insulin on peripheral and splanchnic glucose metabolism in non-insulin-dependent (type II) diabetes mellitus. J Clin Invest 76:149-155

43. Bonadonna R, Groop L, Kraemer N et al (1990) Obesity and insulin resistance in man: a dose response study. Metabolism 39:452-459

44. Bajaj M, DeFronzo RA (2003) Metabolic and molecular basis of insulin resistance. J Nucl Cardiol 10:311-323

45. Shulman GI, Rothman Dl, Jue T et al (1990) Quantitation of muscle glycogen synthesis in normal subjects and subjects with non-insulin-dependent diabetes by ${ }^{13} \mathrm{C}$ nuclear magnetic resonance spectroscopy. N Engl J Med 322:223-238

46. Chen IY-D, Jeng C-Y, Hollenbeck CB et al (1988) Relationship between plasma glucose and insulin concentration, glucose production, and glucose disposal in normal subjects and patients with non-insulin-dependent diabetes. J Clin Invest 82:21-25

47. Reaven G (2003) Insulin resistance, hypertension, and coronary heart disease. J Clin Hypertens 5:269-274

48. Sironi AM, Pingitore A, Ghione S et al (2008) Early hypertension is associated with reduced regional cardiac function, insulin resistance, epicardial, and visceral fat. Hypertension 51:282-288

49. Ferrannini E, Buzzigoli G, Bonadonna R et al (1987) Insulin resistance in essential hypertension. New Eng J Med 317:350-357

50. Solini A, DeFronzo RA (1992) Insulin resistance, hypertension, and cellular ion transport systems. Acta Diabetologica 29:196200

51. DeFronzo RA (1997) Insulin resistance: a multifaceted syndrome responsible for NIDDM, obesity, hypertension, dyslipidaemia and atherosclerosis. Neth J Med 50:191-197

52. Rana JS, Visser ME, Arsenault BJ et al. (2010) Metabolic dyslipidemia and risk of future coronary heart disease in apparently healthy men and women: The EPIC-Norfolk prospective population study. Int $\mathrm{J}$ Cardiol doi:10.1016/j.ijcard 2009.03.123

53. Stamler J, Vaccaro O, Neaton JD et al (1993) Diabetes, other risk factors, and 12-yr cardiovascular mortality for men screened in the Multiple Risk Factor Intervention Trial. Diabetes Care $16: 434-444$

54. Jeppesen J, Hollenbeck CB, Zhou MY et al (1995) Relation between insulin resistance, hyperinsulinemia, postheparin plasma lipoprotein lipase activity, and postprandial lipemia. Arteriosclerosis Thromb Vasc Biol 15:320-324

55. Sheu WH, Shieh SM, Fuh MM et al (1993) Insulin resistance, glucose intolerance, and hyperinsulinemia. Hypertriglyceridemia vs hypercholesterolemia. Arteriosc Throb 13:367-370

56. Galvan AQ, Santoro D, Natali A et al (1993) Insulin sensitivity in familial hypercholesterolemia. Metabolism 42:1359-1364

57. Kudolo GB, Bressler P, DeFronzo RA (1997) Plasma PAF acetylhydrolase in non-insulin dependent diabetes mellitus and obesity: effect of hyperinsulinemia and lovastatin treatment. J Lipid Mediat Cell Signal 17:97-113

58. Howard BV, Robbins DC, Sievers ML et al (2000) LDL cholesterol as a strong predictor of coronary heart disease in diabetic individuals with insulin resistance and low LDL: The Strong Heart Study. Arterioscler Thromb Vasc Biol 20:830 835

59. Bressler P, Bailey S, Matsuda M et al (1996) Insulin resistance and coronary artery disease. Diabetologia 39:1345-1350

60. Paternostro G, Camici PG, Lammerstma AA et al (1996) Cardiac and skeletal muscle insulin resistance in patients with coronary 
heart disease. A study with positron emission tomography. J Clin Invest 98:2094-2099

61. Iozzo P, Chareonthaitawee P, Dutka D et al (2002) Independent association of type 2 diabetes and coronary artery disease with myocardial insulin resistance. Diabetes 51:3020-3024

62. Lautamaki R, Juhani Airaksinen KE, Seppanen M et al (2005) Rosiglitazone improves myocardial glucose uptake in patients with type 2 diabetes and coronary artery disease. Diabetes $54: 2787-2794$

63. Abdul-Ghani M, Tripathy D, DeFronzo RA (2006) Contribution of beta cell dysfunction and insulin resistance to the pathogenesis of impaired glucose tolerance and impaired fasting glucose. Diabetes Care 29:1130-1139

64. Abdul-Ghani M, Jenkinson C, Richardson D et al (2006) Insulin secretion and insulin action in subjects with impaired fasting glucose and impaired glucose tolerance: results from the Veterans Administration Genetic Epidemiology Study (VAGES). Diabetes 55:1430-1435

65. Gulli G, Ferrannini E, Stern M et al (1992) The metabolic profile of NIDDM is fully established in glucose-tolerant offspring of two Mexican-American NIDDM parents. Diabetes 41:15751586

66. Kashyap SR, DeFronzo RA (2007) The insulin resistance syndrome: physiological considerations. Diabetes Vasc Dis Res 4:13-19

67. Hanley AJ, Williams K, Stern MP et al (2002) Homeostasis model assessment of insulin resistance in relation to the incidence of cardiovascular disease: the San Antonio Heart Study. Diabetes Care 25:1177-1184

68. Isomaa B, Almgren P, Tuomi T et al (2001) Cardiovascular morbidity and mortality associated with the metabolic syndrome. Diabetes Care 24:683-689

69. Bonora E, Kiechl S, Willeit J et al (2007) Insulin resistance as estimated by homeostasis model assessment predicts incident symptomatic cardiovascular disease in Caucasian subjects from the general population: the Bruneck Study. Diabetes Care 30:318324

70. Bonora E, Formentini G, Calcaterra F et al (2002) HOMAestimated insulin resistance is an independent predictor of cardiovascular disease in type 2 diabetic subjects: prospective data from the Verona Diabetes Complications Study. Diabetes Care 25:1135-1141

71. Howard G, O'Leary DH, Zaccaro D et al (1996) Insulin sensitivity and atherosclerosis. The Insulin Resistance Atherosclerosis Study (IRAS) Investigators. Circulation 93:1809-1817

72. Bedblad B, Nilsson P, Janzon L et al (2002) Relation between insulin resistance and carotid intima-media thickness and stenosis in non-diabetic subjects. Results from a cross-sectional study in Malmö, Sweden. Diabet Med 17:299-307

73. Ferrannini E, Balkau B, Coppack SW et al (2007) Insulin resistance, insulin response, and obesity as indicators of metabolic risk. J Clin Endocrinol Metab 92:2885-2892

74. D'Agostino RB Sr, Grundy S, Sullivan LM et al (2001) Validation of the Framingham coronary heart disease prediction scores: results of a multiple ethnic groups investigation. JAMA 286:180-187

75. Wilson PWF, D'Agostino RB, Levy D et al (1998) Prediction of coronary heart disease using risk factors categories. Circ 97:1837-1847

76. Goldsen SH, Folsom AR, Coresh J et al (2002) Risk factor groupings related to insulin resistance and their synergistic effects on subclinical atherosclerosis: the atherosclerosis risk in communities study. Diabetes 51:3069-3076

77. Taniguchi CM, Emanuelli B, Kahn CR (2006) Critical nodes in signaling pathways: insights into insulin action. Nat Rev Mol Cell Biol 7:85-96
78. DeFronzo RA (1997) Pathogenesis of type 2 diabetes mellitus: metabolic and molecular implications of identifying diabetes genes. Diabetes Rev 5:177-269

79. White MF, Livingston JN, Backer JM et al (1992) Mutation of the insulin receptor at tyrosine 960 inhibits signal transmission but does not affect its tyrosine kinase activity. Cell 54:641-649

80. Sun XJ, Miralpeix M, Myers MG Jr et al (1992) Expression and function of IRS-1 in insulin signal transmission. J Biol Chem 267:22662-22672

81. Ruderman N, Kapeller R, White MF et al (1990) Activation of phosphatidylinositol-3-kinase by insulin. Proc Natl Acad Sci USA 87:1411-1415

82. Brady MJ, Nairin AC, Saltiel AR (1997) The regulation of glycogen synthase by protein phosphatase 1 in 3T3-I 1 adipocytes. J Biol Chem 272:29698-29703

83. Dent P, Lavoinne A, Nakielny S et al (1990) The molecular mechanisms by which insulin stimulates glycogen synthesis in mammalian skeletal muscle. Nature 348:302-308

84. Osawa H, Sutherland C, Robey R et al (1996) Analysis of the signaling pathway involved in the regulation of hexokinase II gene transcription by insulin. J Biol Chem 272:16690-16694

85. Cross D, Alessi DR, Vandenhead JR et al (1994) The inhibition of glycogen synthase kinase-3 by insulin or insulin-like growth factor 1 in the rat skeletal muscle cell line L6 is blocked by wortmannin but not by rapamycin: evidence that wortmannin blocks activation of the mitogenactivated protein kinase pathway in L6 cells between Ras and Raf. Biochem 303:21-26

86. Steinberg HO, Brechtel G, Johnson A et al (1994) Insulinmediated skeletal muscle vasodilation is nitric oxide dependent: a novel action of insulin to increase nitric oxide release. J Clin Invest 94:1172-1179

87. Zeng G, Nystrom FH, Ravichandran LV et al (2000) Roles of insulin receptor, PI3-kinase, and Akt in insulin-signaling pathways related to production of nitric oxide in human vascular endothelial cells. Circulation 101:1539-1545

88. Montagnani M, Chen H, Barr VA et al (2001) Insulin-stimulated activation of eNOS is independent of $\mathrm{Ca}^{2+}$ but requires phosphorylation by Akt at Ser(1179). J Biol Chem 276:3039230398

89. Brunner H, Cockcroft JR, Deanfield J et al (2005) Endothelial function and dysfunction. Part II: Association with cardiovascular risk factors and diseases. A statement by the Working Group on Endothelins and Endothelial Factors of the European Society of Hypertension. J Hypertens 23:233-246

90. Naruse K, Shimizu K, Muramatsu M et al (1994) Long-term inhibition of NO synthesis promotes atherosclerosis in the hypercholesterolemic rabbit thoracic aorta. PGH2 does not contribute to impaired endothelium-dependent relaxation. Arterioscler Thromb 14:746-752

91. Tokudome T, Horio T, Yoshihara F et al (2004) Direct effects of high glucose and insulin on protein synthesis in cultured cardiac myocytes and DNA and collagen synthesis in cardiac fibroblasts. Metabolism 53:710-715

92. Sasaoka T, Ishiki M, Sawa T et al (1996) Comparison of the insulin and insulin-like growth factor 1 mitogenic intracellular signaling pathways. Endocrinology 137:4427-4434

93. Wang L, Goalstone ML, Draznin B (2004) Molecular mechanisms of insulin resistance that impact cardiovascular biology. Diabetes 53:2735-2740

94. Cusi K, Maezono K, Osman A et al (2000) Insulin resistance differentially affects the PI 3-kinase and MAP kinase-mediated signaling in human muscle. J Clin Invest 105:311-320

95. Jiang ZY, Lin YW, Clemont A et al (1999) Characterization of selective resistance to insulin signaling in the vasculature of obese Zucker (fa/fa) rats. J Clin Invest 104:447-457 
96. Lazer DF, Wiese RJ, Brady MJ et al (1995) Mitogen-activated protein kinase inhibition does not block the stimulation of glucose utilization by insulin. J Biol Chem 270:20801-20807

97. Yuan M, Konstantopoulos N, Lee J et al (2001) Reversal of obesity- and diet-induced insulin resistance with salicylates or targeted disruption of Ikkbeta. Science 293:1673-1677

98. Hirosumi J, Tuncman G, Chang L et al (2002) A central role for JNK in obesity and insulin resistance. Nature 420:333-336

99. Lonroth P, Digirolamo M, Krotkiewski M et al (1983) Insulin binding and responsiveness in fat cells from patients with reduced glucose tolerance and type II diabetes. Diabetes $32: 748-754$

100. Caro JF, Sinha MK, Raju SM et al (1987) Insulin receptor kinase in human skeletal muscle from obese subjects with and without non-insulin dependent diabetes. J Clin Invest 79:1330-1337

101. Nyomba BL, Ossowski VM, Bogardus C et al (1990) Insulinsensitive tyrosine kinase relationship with in vivo insulin action in humans. Am J Physiol 258:E964-E974

102. Freidenberg GR, Reichart D, Olefsky JM et al (1988) Reversibility of defective adipocyte insulin receptor kinase activity in non-insulin dependent diabetes mellitus. Effect of weight loss. J Clin Invest 82:1398-1406

103. Pratipanawatr W, Pratipanawatr T, Cusi K et al (2001) Skeletal muscle insulin resistance in normoglycemic subjects with a strong family history of type 2 diabetes is associated with decreased insulin-stimulated insulin receptor substrate-1 tyrosine phosphorylation. Diabetes 50:2572-2578

104. Pendergrass M, Bertoldo A, Bonadonna R et al (2007) Muscle glucose transport and phosphorylation in type 2 diabetic, obese non-diabetic, and genetically predisposed individuals. Am J Physiol Endocrinol Metab 292:E92-E100

105. Pendergrass M, Koval J, Vogt C et al (1998) Insulin-induced hexokinase II expression is reduced in obesity and NIDDM. Diabetes 47:387-394

106. Kashyap SR, Roman LJ, McLain J et al (2005) Insulin resistance is associated with impaired nitric oxide synthase (NOS) activity in skeletal muscle of type 2 diabetic subjects. J Clin Endocrinol Metab 90:1100-1105

107. Kashyap S, Lara A, Zhang R et al (2008) Insulin reduces plasma arginase activity in type 2 diabetes patients. Diabetes Care 31:134-139

108. Baron AD (1994) Hemodynamic actions of insulin. Am J Physiol 267:E187-E202

109. Cabellero AE, Arora S, Saouaf R et al (1999) Microvascular and macrovascular reactivity is reduced in subjects at risk for type 2 diabetes. Diabetes 48:1856-1862

110. Cerosismo E, DeFronzo RA (2006) Insulin resistance and endothelial dysfunction: the road map to cardiovascular diseases. Diab Metab Res Rev 22:423-436

111. Ross R (1993) The pathogenesis of atherosclerosis: a perspective for the 1990s. Nature 362:801-809

112. Hsueh WA, Lyon CJ, Quiñones MJ (2004) Insulin resistance and the endothelium. Am J Med 117:109-117

113. Behrendt D, Ganz P (2002) Endothelial function. From vascular biology to clinical applications. Am J Cardiol $21: 40 \mathrm{~L}-48 \mathrm{~L}$

114. Draznin B (2006) Molecular mechanisms of insulin resistance: serine phosphorylation of insulin receptor substrate- 1 and increased expression of p85alpha: the two sides of a coin. Diabetes 55:2392-2397

115. Aguirre V, Werner Ed, Giraud J et al (2002) Phosphorylation of Ser307 in insulin receptor substrate-1 blocks interactions with the insulin receptor and inhibits insulin action. J Biol Chem 277:1531-1537

116. Liu YF, Herschkovitz A, Boura-Halfon S et al (2004) Serine phosphorylation proximal to its phosphotyrosine binding domain inhibits insulin receptor substrate 1 function and promotes insulin resistance. Mol Cell Biol 24:9668-9681

117. Sasaoka T, Rose DW, Jhun BH et al (1994) Evidence for a functional role of Shc proteins in mitogenic signaling induced by insulin, insulin-like growth factor-1, and epidermal growth factor. J Biol Chem 269:13689-13694

118. Hsueh WA, Law RE (1999) Insulin signaling in the arterial wall. Am J Cardiol 84:21J-24J

119. Lettner JW, Kline T, Carel K et al (1997) Hyperinsulinemia potentiates activation of p 21 Ras by growth factors. Endocrinol 138:2211-2214

120. Golovchenko I, Goalstone ML, Watson P et al (2000) Hyperinsulinemia enhances transcriptional activity of nuclear factor-kB induced by angiotensin II, hyperglycemia, and advanced glycosylation end products in vascular smooth muscle cells. Circ Res 87:746-762

121. Hajra L, Evans AI, Chen M et al (2000) The NF-kappa B signal transduction pathway in aortic endothelial cells is primed for activation in regions predisposed to atherosclerotic lesion formation. PNAS 97:9052-9057

122. de Winther MP, Kanters E, Kraal G et al (2005) Nuclear factor kappaB signaling in atherogenesis. Art Throm Vasc Biol 25:904 914

123. Gao Z, Hwang D, Bataille F et al (2002) Serine phosphorylation of insulin receptor substrate 1 by inhibitor kappa B kinase complex. J Biol Chem 277:48115-48121

124. Folli F, Kahn CR, Hansen H, Bouchie JL, Feener EP (1997) Angiotensin II inhibits insulin signaling in aortic smooth muscle cells at multiple levels. J Clin Invest 100:2158-2169

125. Uusitupa MI, Niskanen LK, Siitonen O et al (1993) Ten-year cardiovascular mortality in relation to risk factors and abnormalities in lipoprotein composition in type 2 (non-insulindependent) diabetic and non-diabetic subjects. Diabetologia 36:1175-1184

126. Miyazaki Y, He H, Mandarino LJ et al (2003) Rosiglitazone improves downstream insulin-receptor signaling in type 2 diabetic patients. Diabetes 52:1943-1950

127. Bajaj M, Baig R, Suraamornkul S et al. (2010) Effects of pioglitazone on intramyocellular fat metabolism in patients with type 2 diabetes mellitus. J Clin Endocrinol Metab doi:10.1210/ jc.2009-0911

128. Vinik AI, Stansberry KB, Barlow PM (2003) Rosiglitazone treatment increased nitric oxide production in human peripheral skin: a controlled clinical trial in patients with type 2 diabetes mellitus. J Diab Comp 17:279-285

129. Natali A, Baldeweg S, Toschi E et al (2004) Vascular effects of improving metabolic control with metformin or rosiglitazone in type 2 diabetes. Diabetes Care 27:1349-1357

130. Pistrosch F, Passauer J, Fischer S et al (2004) In type 2 diabetes, rosiglitazone therapy for insulin resistance ameliorates endothelial dysfunction independent of glucose control. Diabetes Care 27:484-490

131. Bays H, Mandarino L, DeFronzo RA (2004) Role of the adipocytes, FFA, and ectopic fat in the pathogenesis of type 2 diabetes mellitus: PPAR agonists provide a rational therapeutic approach. J Clin Endocrinol Metab 89:463-478

132. Unger RH (2003) Lipid overload and overflow: metabolic trauma and the metabolic syndrome. Trends Endocrinol Metab $14: 398-403$

133. Kashyap S, Belfort R, Berria R et al (2004) Discordant effects of a chronic physiological increase in plasma FFA on insulin signaling in healthy subjects with or without a family history of type 2 diabetes. Am J Physiol Endocrinol Metab 287:E537E546

134. Richardson DK, Kashyap S, Bajaj M et al (2005) Lipid infusion induces an inflammatory/fibrotic response and decreases expres- 
sion of nuclear encoded mitochondrial genes in human skeletal muscle. J Biol Chem 280:10290-10297

135. Dresner A, Laurent D, Marcucci M et al (1999) Effects of free fatty acids on glucose transport and IRS-1-associated phosphatidylinositol 3-kinase activity. J Clin Invest 103:253-259

136. Kashyap S, Belfort R, Gastaldelli A et al (2003) A sustained increase in plasma free fatty acids impairs insulin secretion in non-diabetic subjects genetically predisposed to develop type 2 diabetes. Diabetes 52:2461-2474

137. Belfort R, Mandarino L, Kashyap S et al (2005) Dose response effect of elevated plasma FFA on insulin signaling. Diabetes 54:1640-1648

138. Mayerson AB, Hundal RS, Dufour S et al (2002) The effects of rosiglitazone on insulin sensitivity, lipolysis, and hepatic and skeletal muscle triglyceride content in patients with type 2 diabetes. Diabetes 51:797-802

139. Belfort R, Harrison SA, Brown K et al (2006) A placebo controlled trial of pioglitazone in patients with non-alcoholic steatohepatitis. NEJM 355:2297-2307

140. Miyazaki Y, Mahankali A, Matsuda M et al (2002) Effect of pioglitazone on abdominal fat distribution and insulin sensitivity in type 2 diabetic patients. J Clin Endocrinol Metab 87:27842791

141. Bajaj M, Suraamornkul S, Pratipanawatr T et al (2003) Pioglitazone reduces hepatic fat content and augments splanchnic glucose uptake in patients with type 2 diabetes mellitus. Diabetes 52:1364-1370

142. Griffin ME, Marcucci MJ, Cline GW et al (1999) Free fatty acidinduced insulin resistance is associated with activation of protein kinase $\mathrm{C}$ theta and alterations in the insulin signaling cascade. Diabetes 48:1270-1274

143. Bajaj M, Suraamornkul S, Romanelli A et al (2005) Effect of sustained reduction in plasma free fatty acid concentration on intramuscular long chain-fatty acyl-CoAs and insulin action in patients with type 2 diabetic patients. Diabetes 54:3148-3153

144. Kim JK, Fillmore JJ, Chen Y et al (2001) Tissue-specific overexpression of lipoprotein lipase causes tissue-specific insulin resistance. PNAS 98:7522-7527

145. Gao Z, Zhang X, Zuberi A et al (2004) Inhibition of insulin sensitivity by free fatty acids requires activation of multiple serine kinases in 3T3-L1 adipocytes. Mol Endocrinol 18:2024-2034

146. Morino K, Neschen S, Bliz S et al (2008) Muscle-specific IRS-1 Ser->Ala transgenic mice are protected from fat-induced insulin resistance in skeletal muscle. Diabetes 57:2644-2651

147. Yu CL, Chen Y, Cline GW et al (2002) Mechanism by which fatty acids inhibit insulin activation of insulin receptor substrate1 (IRS-1)-associated phosphatidylinositol 2-kinase activity in muscle. J Biol Chem 277:50230-50236

148. Itani SI, Ruderman NB, Schmieder F et al (2002) Lipid-induced insulin resistance in human muscle is associated with changes in diacylglycerol, protein kinase C, and I kappa B-alpha. Diabetes 51:2005-2011

149. Heydrick SJ, Ruderman NB, Kurowski TG et al (1991) Enhanced stimulation of diacylglycerol and lipid synthesis by insulin in denervated muscle. Altered protein kinase C activity and possible link to insulin resistance. Diabetes 40:1707-1711

150. Adams JM, Pratipanawatr T, Berria R et al (2004) Ceramide content is increased in skeletal muscle from obese insulin resistant humans. Diabetes 53:25-31

151. Haus JM, Kashyap SR, Kasumov T et al (2009) Plasma ceramides are elevated in obese subjects with type 2 diabetes and correlate with the severity of insulin resistance. Diabetes 58:337-343

152. Evans JL, Goldfine ID, Maddux BA et al (2002) Oxidative stress and stress-activated signaling pathways: a unifying hypothesis of type 2 diabetes. Endocr Rev 23:599-622
153. Garg R, Tripathy D, Dandona P (2003) Insulin resistance as a proinflammatory state: mechanisms, mediators, and therapeutic interventions. Curr Drug Targets 4:487-492

154. Pickup JC, Crook MA (1998) Is type II diabetes mellitus a disease of the innate immune system? Diabetologia 41:1241-1248

155. Ghanim H, Garg R, Aljada A et al (2001) Suppression of nuclear factor-kappa $\beta$ by troglitazone: evidence for an antiinflammatory effect and a potential antiatherosclerotic effect in the obese. J Clin Endocrinol Metab 86:1306-1312

156. Barnes PJ, Karin M (1997) Nuclear factor-kappaB: a pivotal transcription factor to chronic inflammatory diseases. $\mathrm{N}$ Engl $\mathrm{J}$ Med 336:1066-1071

157. Yamamoto Y, Gaynor RB (2004) IkappaB kinases: key regulators of the NF-kappaB pathway. Trends Biochem Sci 29:72-79

158. De Alvaro C, Teruel T, Hernandez R et al (2004) Tumor necrosis factor alpha produces insulin resistance in skeletal muscle by activation of inhibitor kappaB kinase in a p38 MAPK-dependent manner. J Biol Chem 279:17070-17078

159. Sriwijitkamol A, Christ-Roberts C, Berria R et al (2006) Reduced skeletal muscle inhibitor of kappaB beta content is associated with insulin resistance in subjects with type 2 diabetes: reversal by exercise training. Diabetes 55:760-767

160. Sinha S, Perdomo G, Brown JF et al (2004) Fatty acid-induced insulin resistance in L6 myotubes is prevented by inhibition of activation and nuclear localization of nuclear factor kappa B. J Biol Chem 279:41294-41301

161. Bhatt BA, Dube JJ, Dedousis N et al (2006) Diet-induced obesity and acute hyperlipidemia reduce IkappaBalpha levels in rat skeletal muscle in a fiber-type dependent manner. Am J Physiol Regu Integr Comp Physiol 290:R233-R240

162. Reyna SM, Ghosh S, Tantiwong P et al (2008) Elevated toll-like receptor 4 expression and signaling in muscle from insulinresistant subjects. Diabetes 57:2595-2602

163. Perbal B (2004) CCN proteins: multifunctional signaling regulators. Lancet 363:62-64

164. Cicha I, Yilmaz A, Klein $M$ et al (2005) Connective tissue growth factor is overexpressed in complicated atherosclerotic plaques and induces mononuclear cell chemotaxis in vitro. Art Throm Vas Biol 25:1008-1013

165. Steinberg HO, Chaker H, Leaming R et al (1996) Obesity/insulin resistance is associated with endothelial dysfunction. Implications for the syndrome of insulin resistance. J Clin Invest 97:2601-2610

166. Steinberg HO, Tarshoby M, Monestel R et al (1997) Elevated circulating free fatty acid levels impair endothelium-dependent vasodilation. J Clin Invest 100:1230-1239

167. Wellen KE, Hotamisligil GS (2003) Obesity-induced inflammatory changes in adipose tissue. J Clin Invest 112:1785-1788

168. Lapidus L, Bengtsson C, Larsson B et al (1984) Distribution of adipose tissue and risk of cardiovascular disease and death: a 12 year follow up of participants in the population study of women in Gothenburg, Sweden. BMJ 289:1257-1261

169. Despre JP, Moorjani S, Lupien PJ et al (1990) Regional distribution of body fat, plasma lipoproteins, and cardiovascular disease. Arterioscler Thromb Vas Biol 10:497-511

170. Anderson JW, Kendall CW, Jenkins DJ (2003) Importance of weight management in type 2 diabetes: review with metaanalysis of clinical studies. J Am Coll Nutr 22:331-339

171. Triplitt C, DeFronzo RA (2006) Exenatide: first in class incretin mimetic for the treatment of type 2 diabetes mellitus. Expert Rev Endocrinol Metab 1:329-341

172. Miyazaki Y, Glass L, Triplitt C et al (2001) Effect of rosiglitazone on glucose and free fatty acid metabolism in type 2 diabetic patients. Diabetologia 44:2210-2219

173. Miyazaki Y, Mahankali A, Matsuda M et al (2001) Improved glycemic control and enhanced insulin sensitivity in liver and 
muscle in type 2 diabetic subjects treated with pioglitazone. Diabetes Care 24:710-719

174. Gastaldelli A, Miyazaki Y, Mahankali A et al (2006) The effect of pioglitazone on the liver. Diabetes Care 29:2275-2281

175. Coletta DK, Sriwijitkamol A, Wajcberg E et al (2009) Pioglitazone stimulates AMPK signaling and increases the expression of genes involved in adiponectin signaling. Mitochondrial function and fat oxidation in human skeletal muscle in vivo. Diabetologia 52:723732

176. Petersen KF, Befroy D, Dufour S et al (2003) Mitochondrial dysfunction in the elderly: possible role in insulin resistance. Science 300:1140-1142

177. Petersen KF, Dufour S, Shulman GI (2005) Decreased insulinstimulated ATP synthesis and phosphate transport in muscle of insulin-resistant offspring of type 2 diabetic parents. PLoS Medicine 2:879-884

178. Phielix E, Schrauwen-Hinderling VB, Mensink M et al (2008) Lower intrinsic ADP-stimulated mitochondrial respiration underlies in vivo mitochondrial dysfunction in muscle of male type 2 diabetic patients. Diabetes 57:2943-2949

179. Abdul-Ghani MA, DeFronzo RA (2008) Mitochondrial dysfunction, insulin resistance, and type 2 diabetes mellitus. Curr Diab Rep 8:173-178

180. Abdul-Ghani MA, Jani R, Chavez A et al (2009) Mitochondrial reactive oxygen species generation in obese non-diabetic and type 2 diabetic participants. Diabetologia 52:574-582

181. Abdul-Ghani MA, Muller FL, Liu Y et al (2008) Deleterious action of FA metabolites on ATP synthesis: possible link between lipotoxicity, mitochondrial dysfunction, and insulin resistance. Am J Physiol 295:E678-E685

182. Patti ME, Butte AJ, Crunkhorn S et al (2003) Coordinated reduction of genes of oxidative metabolism in humans with insulin resistance and diabetes: potential role of PGC1 and NRF1. Proc Natl Acad Sci USA 100:8466-8471

183. Puigserver P, Spiegelman BM (2003) Peroxisome proliferatoractivated receptor-gamma coactivator 1 alpha (PGC-1 alpha): transcriptional coactivator and metabolic regulator. Endocr Rev 24:78-90

184. Yamauchi T, Kamon J, Waki H et al (2001) The fat-derived hormone adiponectin reverses insulin resistance associated with both lipoatrophy and obesity. Nat Med 7:941-946

185. Yamauchi T, Kadowaki T (2008) Physiological and pathophysiological roles of adiponectin and adiponectin receptors in the integrated regulation of metabolic and cardiovascular diseases. Int J Obesity 32:S13-S18

186. Kubota N, Terauchi Y, Yamauchi T et al (2002) Disruption of adiponectin causes insulin resistance and neointimal formation. $\mathrm{J}$ Biol Chem 277:25863-25866

187. Civitarese AE, Jenkinson CP, Richardson D et al (2004) Adiponectin receptor gene expression and insulin sensitivity in non-diabetic Mexican Americans with or without family history of type 2 diabetes. Diabetologia 47:816-820

188. Civitarese AE, Ukropcova B, Carling S et al (2006) Role of adiponectin in human skeletal muscle bioenergetics. Cell Metab 4:74-87

189. Miyazaki Y, Glass L, Triplitt C et al (2002) Abdominal fat distribution and peripheral and hepatic insulin resistance in type 2 diabetes mellitus. Am J Physiol Endocrinol Metab 46:E1135E1143

190. Kelly JE, Hans TS, Walsh K et al (1999) Effects of a thiazolidinedione compound on body fat and fat distribution of patients with type 2 diabetes. Diabetes Care 22:288-293

191. Aithal GP, Thomas JA, Kaye PV et al (2008) Randomized, placebo-controlled trial of pioglitazone in nondiabetic subjects with nonalcoholic steatohepatitis. Gastroenterology 135:11761184

192. Gastaldelli A, Ferrannini E, Miyazaki Y et al (2007) Thiazolidinediones improve beta-cell function in type 2 diabetic patients. Am J Phyisol Endocrinol Metab 292:E871-E883

193. Moibi JA, Gupta D, Jetton TL et al (2007) Peroxisome proliferator-activated receptor-gamma regulates expression of PDX-1 and NKX6.1 in INS-1 cells. Diabetes 56:88-95

194. Matsui J, Terauchi Y, Kubota N et al (2004) Pioglitazone reduces islet triglyceride content and restores impaired glucosestimulated insulin secretion in heterozygous peroxisome proliferator-activated receptor-gamma-deficient mice on a highfat diet. Diabetes 53:2844-2854

195. Del Prato S, Marchetti P (2004) Targeting insulin resistance and beta-cell dysfunction: the role of thiazolidinediones. Diabetes Tech Thera 6:719-731

196. Lupi R, del Guerra S, Marselli L et al (2004) Rosiglitazone prevents the impairment of human islet function induced by fatty acids: evidence for a role of PPARgamma2 in the modulation of insulin secretion. Am J Physiol Endocrinol Metab 286:E560-E567

197. Sharma S, Adrogue JV, Golfman L et al (2004) Intramyocardial lipid accumulation in the failing human heart resembles the lipotoxic rat heart. FASEB J 18:1692-1700

198. Kankaanpaa M, Lehto HR, Parkka JP et al (2006) Myocardial triglyceride content and epicardial fat mass in human obesity: relationship to left ventricular function and serum free fatty acid levels. J Clin Endocrinol Metab 91:4689-4695

199. McGavock JM, Lingvay I, Zib I et al (2007) Cardiac steatosis in diabetes mellitus: a ${ }^{1} \mathrm{H}$-magnetic resonance spectroscopy study. Circulation 116:1170-1175

200. Zib I, Jacob AN, Lingvay I et al (2007) Effect of pioglitazone therapy on myocardial and hepatic steatosis in insulin-treated patients with type 2 diabetes. J Investig Med 55:230-236

201. Deeg MA, Buse JB, Goldberg RB et al (2007) Pioglitazone and rosiglitazone have different effects on serum lipoprotein particle concentrations and sizes in patients with type 2 diabetes and dyslipidemia. Diabetes Care 30:2458-2464

202. Chiquette E, Ramirez G, DeFronzo R (2004) A meta-analysis comparing the effect of thiazolidinediones on cardiovascular risk factors. Arch Intern Med 164:2097-2104

203. Miyazaki M, de Filippis E, Bajaj M et al (2005) Predictors of improved glycaemic control with rosiglitazone therapy in type 2 diabetic patients: a practical approach for the primary care physician. Br J Diabetes Vasc Dis 5:28-35

204. Dormandy JA, Charbonnel B, Eckland DJ et al (2005) Proactive investigators: secondary prevention of macrovascular events in patients with type 2 diabetes in the PROactive Study (PROspective pioglitazone Clinical Trial in macroVascular Events): a randomized controlled trial. Lancet 266:1279-1289

205. Lincoff AM, Wolski K, Nicholls SJ et al (2007) Pioglitazone and risk of cardiovascular events in patients with type 2 diabetes mellitus: a meta-analysis of randomized trials. JAMA 298:1180-1188

206. Mazzone T, Meyer PM, Feinstein SB et al (2006) Effect of pioglitazone compared with glimepiride on carotid intimamedia thickness in type 2: a randomized trial. JAMA 296: 2572-2581

207. Nissen SE, Nicholls SJ, Wolski K et al (2008) Comparison of pioglitazone vs glimepiride on progression of coronary atherosclerosis in patients with type 2 diabetes: the Periscope randomized controlled trial. JAMA 299:1561-1573

208. Sarruf DA, Yu F, Nguyen HT et al (2008) Expression of peroxisome proliferator-activated receptor-gamma in key neuronal subsets regulating glucose metabolism and energy homeostasis. Endocrinology 150:707-712 